\title{
RECENT LEGISLATIVE AND REGULATORY DEVELOPMENTS OF INTEREST TO OIL AND GAS LAWYERS
}

\author{
TERRANCE M. HUGHES, HAROLD R. HUBER \\ and SEAN J. KORNEY ${ }^{*}$
}

The purpose of this article is to provide a brief review of recent legislative and regulatory developments of particular interest to oil and gas lawyers. Part II deals with legislative developments, reporting recent changes in statutes and regulations. Federal and Alberta legislative developments and certain noteworthy developments in British Columbia and Saskatchewan are reported. Part III of the article considers regulatory developments with respect to decisions made at both the federal and provincial levels. At the federal level. the authors examine recent decisions of the National Energy Board. The authors also examine decisions made by the Alberta Energy and Utilities Board and the British Columbia Utilities Commission.

\section{TABLE OF CONTENTS}

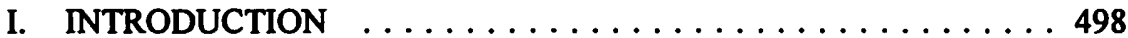

II. LEGISLATIVE DEVELOPMENTS $\ldots \ldots \ldots \ldots \ldots \ldots \ldots \ldots 499$

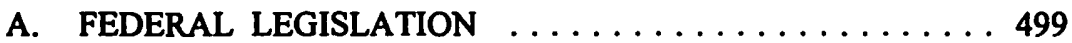

B. ALBERTA LEGISLATION $\ldots \ldots \ldots \ldots \ldots \ldots \ldots \ldots$

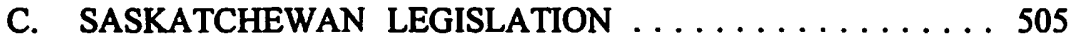

D. BRITISH COLUMBIA LEGISLATION $\ldots \ldots \ldots \ldots \ldots 508$

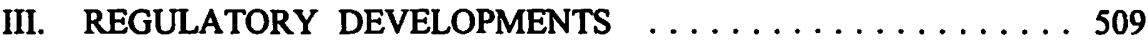

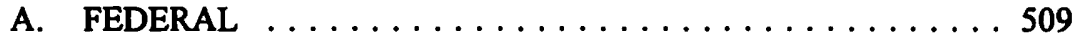

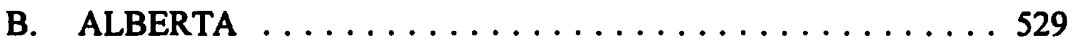

C. BRITISH COLUMBIA $\ldots \ldots \ldots \ldots \ldots \ldots \ldots \ldots 51$

\section{INTRODUCTION}

The purpose of this article is to discuss those legislative and regulatory developments which have occurred during the period June, 1995 through May 1996 which are of particular interest to oil and gas lawyers. Included in this review will be changes in statutes and regulations and the decisions, directives and published policy statements of selected administrative bodies. In order to place a limit on the scope of the article, federal and Alberta legislative and regulatory developments are reported in detail and certain significant developments in British Columbia and Saskatchewan are also discussed. 


\section{LEGISLATIVE DEVELOPMENTS}

\section{A. FEDERAL LEGISLATION}

\section{Statutes}

\section{a. National Energy Board Act}

The Canada Transportation $A c t^{2}$ contains a consequential amendment to the definition of "pipeline" in the NEB. The amendment expands the definition of a pipeline to now include a line that is used or intended to be used to transport any commodity other than a sewer or water pipeline used or intended to be used exclusively for municipal purposes. Previously, the definition of pipeline only included pipelines that transported oil or gas or commodities that could be transported with oil and gas. Other consequential amendments were also made.

\section{Regulations}

\section{a. Canada Oil and Gas Operations $\mathrm{Act}^{3}$}

Canada Oil and Gas Geophysical Operations Regulations ${ }^{4}$

These comprehensive new regulations establish a standard set of procedures to be followed prior to, during and following geophysical operations onshore and offshore in connection with Canada lands which are not covered under an accord agreement with an adjoining province. The primary objective of the regulations is to ensure safe geophysical operations with a minimal amount of environmental impact.

\section{b. National Energy Board Act}

\section{(i) National Energy Board Export and Import Reporting Regulations ${ }^{5}$}

The National Energy Board ("NEB") has been engaged in a lengthy process to revise the National Energy Board Part VI Regulations. ${ }^{6}$ It was proposed that amendments would be made to these regulations in order to change the provisions relating to oil and gas, issue new regulations with respect to reporting requirements and issue new regulations relating to electricity. On November 28, 1995 the new reporting requirements were implemented. The new regulations specify the information which must be filed by a holder of an order, permit or licence issued under Part VI of the $N E B A C t$ in respect of either the exportation or importation of gas and the exportation of propane, butanes, ethane, oil and electricity.

R.S.C. 1985 , c. N-7 [hereinafter $N E B$ Act].

Bill C-14, An Act to Continue the National Transportation Agency as the Canadian Transportation Agency, 2d Sess., 35th Parl., 1996, ss. 237-245.

S.C. 1992 , c. 35 .

SOR/96-117.

SOR/95-563.

C.R.C., 1978, c. 1056. 


\section{(ii) National Energy Board Part VI (Oil and Gas) Regulations ${ }^{7}$}

The NEB issued its first draft of proposed Part VI (Oil and Gas) Regulations in August 1990. At the time, the draft was subject of numerous comments by industry participants. In February 1995, the NEB released a revised proposal for the Part VI (Oil and Gas) Regulations which would have imposed more stringent requirements on the holder of a gas export licence in respect of changes to its gas supply arrangements. The proposed addition of this requirement was opposed by most industry participants. On January 15, 1996 the NEB issued a revised draft of proposed Part VI (Oil and Gas) Regulations for further comment. This draft removed the February 1995 proposed requirement for a licence holder to file changes to its gas supply arrangements. The new draft also reduced the level of gas supply information that was required to be filed in support of a gas export licence application. On May 15, 1996, the NEB's January 15, 1996 draft of the Part VI (Oil and Gas) Regulations was implemented. The Part VI (Oil and Gas) Regulations are structured to provide separate sections for natural gas, propane, butanes, ethane, and oil. These regulations set out the information to be furnished by applicants for export licences and orders. With respect to gas export licences, they prescribe the form to be utilized for summarizing the terms of the applicant's gas export sales contract and the required gas supply information including a general gas supply and demand balance for a non-dedicated supply.

The regulations contain a detailed definition as to what constitutes a "gas export sales contract" which, in some cases, may now be an upstream gas purchase contract if there is an affiliate relationship between the holder of a licence and the importer. Any amendment, agreement or change pertaining to a gas export sales contract is required to be filed with the NEB within thirty days after execution and the holder of a licence is prohibited from exporting pursuant to or in accordance with any amendment, agreement or change pertaining to the gas export sales contract unless such amendment, agreement or change has been approved by the NEB. The NEB may approve an amendment, agreement or change where the NEB determines that gas will continue to be exported under the licence. Upon the request of the NEB, the holder of a licence is now also required to file a copy of every contract, other than a gas export sales contract, pertaining to the exportation of gas authorized by the licence and every amendment, agreement or change pertaining thereto. 


\section{B. ALBERTA LEGISLATION}

1. Statutes

\section{a. Alberta Energy and Utilities Board Act ${ }^{8}$}

The Alberta Energy and Utilities Board Statutes Amendment Act ${ }^{9}$ expands certain administrative powers of the Alberta Energy and Utilities Board ("EUB"). It allows the EUB to hire persons who are necessary for the transaction of the EUB's business, including consultants who have special knowledge or skills that relate to any matters that may be the subject of an EUB inquiry. In addition, the amendment also provides for the administration of certain financial matters of the EUB. The EUB is now authorized to impose administrative fees on any facility, scheme or operation that is subject to any enactment that is administered by the EUB. The EUB can establish the level of the administration fees to produce a sum that is sufficient to defray a portion or all of the estimated net expenditures of the EUB for the fiscal year. Any prescribed administration fee with respect to a facility is payable by the operator of the facility. To finance its operations, the EUB is permitted to borrow funds to defray current expenses, secured against administrative fees receivable.

\section{b. Environmental Protection and Enhancement Act}

Pursuant to s. 11 of the Miscellaneous Statutes Amendment Act, 1995, "the power of the Minister of Environmental Protection to make regulations concerning the concentration, amount, level, rate, measurement, point of measurement and visible emissions of substances that can be released into the environment is transferred to the Lieutenant Governor in Council. The minister must now engage in public consultations as the minister considers appropriate in the circumstances prior to the enactment of any such regulations by the Lieutenant Governor in Council. The minister remains responsible for making regulations classifying releases and exempting any releases from the application of the Act.

\section{c. Oil and Gas Conservation Act ${ }^{12}$}

The Energy Statutes Amendment Act, $1996^{13}$ amended the Oil and Gas Conservation Act to expand the EUB's power in respect of common carrier, common purchaser and common processor declarations. In order to give effect to a declaration the EUB may now direct:

$\begin{array}{ll}8 & \text { S.A. 1994, c. A-19.5. } \\ \text { 10 } & \text { S.A. 1996, c. } 8 . \\ \text { 11 } & \text { S.A. 1992, c. E-13.3. } \\ \text { 12 } & \text { S.A. } 1995, \text { c. } 23 . \\ 13 & \text { R.S.A. } 1980 \text {, c. O-5. } \\ & \text { S.A. 1996, c. } 18 .\end{array}$


(1) the point at which a common carrier or common purchaser shall take delivery of production and the proportion of production that it shall take;

(2) the point at which a common purchaser shall take delivery of gas and the proportion of gas it shall take; and

(3) the proportion of gas that a common processor shall process and the total amount of gas that shall be processed.

2. Regulations

a. Gas Resources Preservation Act ${ }^{14}$

Approval of Short-Term Permits Regulation ${ }^{15}$

This regulation removes the requirement to obtain the approval of the Minister of Energy under s. 6 of the Gas Resources Preservation Act where a party is applying for a short-term gas removal permit or an amendment to a short-term permit. This relaxation does not apply where the gas is a mixture of mainly ethane. Accordingly, short-term permits are now completely under the authority of the EUB.

b. Natural Gas Marketing Act ${ }^{16}$

Natural Gas Marketing Amendment Regulation ${ }^{17}$

This regulation replaces Parts 3 and 4 of the Natural Gas Marketing Regulations. ${ }^{18}$ Part 3 deals with records and information to be filed with the Alberta Petroleum Marketing Commission ("APMC"), while Part 4 restates the procedure for an appeal of a decision of the APMC under Part 1 or Part 2 of the Natural Gas Marketing Act. The notable changes are:

(1) the addition of new specifications for reporting on acquisitions of marketable gas in Alberta;

(2) the addition of new specifications for monthly statements regarding production, transportation, sale, purchase, distribution, use or other disposition of marketable gas in Alberta; removal or sale of marketable gas from Alberta; and importation of gas into Alberta;

(3) the addition of provisions that allow the APMC to impose an automatic penalty of $\$ 1,000$ for any failure to furnish a necessary report and a discretionary penalty of up to $\$ 10,000$ for furnishing an inaccurate or incomplete report; however, s. 18(a) provides that information will only be

\footnotetext{
S.A. 1984, c. G-3.1.

Alta. Reg. 272/95.

S.A. 1986 , c. $\mathrm{N}-2.8$.

Alta. Reg. 25/96.

Alta. Reg. 358/86.
} 
classified as being inaccurate if it is not in accordance with the records kept by the reporter;

(4) the APMC may waive any penalty prior to January 1998 on the grounds that a person was not aware of the reporting requirement;

(5) any penalty imposed by the APMC is subject to an appeal to the Minister of Energy; and

(6) a new obligation on persons who transport marketable gas or have marketable gas transported in Alberta for their account to keep records relating thereto for five years.

c. Licensing of Trade and Business Act ${ }^{19}$

Natural Gas Direct Marketing Regulations ${ }^{20}$

These regulations stipulate a bonding system and code of conduct for agents, marketers and brokers involved in direct supply arrangements with core customers. They also prescribe a form of disclosure statement which must be completed and signed by the consumer and attached to any agreement entered into with the marketer.

\section{Information Letters}

\section{a. Alberta Energy Information Letter 96-11}

Information Letter 96-11 addresses changes to the mineral expiry process and was formulated jointly by the Alberta Department of Energy ("Department") and the EUB. This information letter supplements EUB Guide G-29: Well Abandonment Guide. Some of the more important changes are as follows:

(1) effective April 1, 1996, Crown lessees will no longer be given one year from the effective date of the cancellation or expiry of a lease to abandon, re-enter or convert a well into a service well;

(2) where notification has been given by the Department prior to April 1, 1996, the Crown lessee will have one year to abandon the well;

(3) upon expiry of the mineral rights, the Department will notify the EUB, which in turn will initiate well abandonment proceedings;

(4) the EUB will be responsible for granting extensions to the abandonment deadline; 
(5) the lessee, licensee or permittee must notify the Department if it wishes to link a non-abandoned well to a different active mineral agreement; and

(6) the EUB will be responsible for processing applications to re-enter existing wellbores.

\section{b. Alberta Energy Information Letter 96-14}

Information Letter 96-14 dated May 7, 1996 establishes new policies for the Department, implementing a number of changes in business rules designed to improve and simplify Department policy in the areas of lease continuation, licence administration, offset obligations, transfers, sales and other general matters.

For example, s. 96 continuation under the Mines and Minerals $A c t^{21}$ is now automatic upon application without the submission of technical data for one lease to a maximum of five sections or for all expiring leases within a single section. If a lessee wishes to continue more than five sections technical data must be presented. This proposal is designed to reduce administrative burdens for both the Department and industry.

The scope of the data that may be considered under an application for continuation under ss. 95 or 97 is broader, generally providing more instances in which continuation may be granted. Under the new policies, the lessee will be held more responsible for its continuation application but the process will be simplified. Section 97 security will be more easily and frequently refunded. A greater effort will be made between the Department and the EUB to identify suspended wells and for the Department to issue a s. 98 notice and the EUB to issue an abandonment order on non-productive wells. Some of the above-described changes will be implemented later this year.

The requirement for technical data in support of a grouping application where the well is located more than 3.2 kilometres from the undrilled licence will be eliminated. Re-entries of existing wells will be allowed to earn leases if at least 150 metres of additional meterage is drilled or, where less than 150 metres are drilled, if the Department determines that the operations have provided significant new information. A re-entry will not earn leases if it simply re-evaluates or tests a zone that had already been penetrated or logged but a lease for the spacing unit will be issued. Horizontal and directional wells will earn leases from licences based on measured total depth which includes the horizontal portion of the wellbore instead of true vertical depth.

The Department will treat the Mannville geological group as a single formation for the purpose of serving and satisfying offset notices.

The need for corporate seals and affidavits of execution for transfers has been removed, but the signatory must indicate the capacity in which they are signing. Section 
97 security will be refunded to the party which gave the security, not the current owner. The transfer forms will be simplified later this year.

Private sales will be permitted where an operator proposes to purchase Crown rights that comprise less than 50 percent of a spacing unit and the operator already owns the freehold portion. Private sales will also be permitted for a single substance where the applicant already controls the other substance under an existing lease.

Where a portion of any wellbore has been drilled or is proposed to be drilled into a road allowance adjoining a lease, the operator must obtain authorization from the Department and may obtain a lease of the road allowance rights for a bonus fee of $\$ 1,000$. Transfers will now be accepted for leases that are expired but not cancelled. All interests in an agreement will now have to be recorded as decimals and not fractions. Pending transfers will now be included in Crown search letters in the "General Remarks" section. The processing of complete and partial surrenders will be simplified by prescribing a standard form later this year.

\section{SASKATCHEWAN LEGISLATION}

\section{Statutes}

\section{a. The Crown Minerals $\mathrm{Act}^{22}$}

The Crown Minerals Act has been amended by The Crown Minerals Amendment Act, $1995^{23}$ in three respects. First, the provisions for appealing any determination by the Minister of Energy and Mines of the quantum of royalty payable have been amended to clarify the procedure for making such an appeal. Secondly, provisions have been added to the Act to empower the minister to create and register, in the Court of Queen's Bench, a "certificate" describing any overdue royalties, rents, fees, dues or charges. In the case of an overdue royalty where a determination has not been made, the payor must acknowledge that the royalty was payable before the minister can register the certificate. If a payor does acknowledge that it owes overdue royalties, the minister may include interest and penalties on the overdue royalties described in the certificate. A registered certificate has the same force and effect as a judgment of the Court of Queen's Bench and the minister may issue a garnishee summons to any third party indebted to the royalty payor. The payor may appeal any certificate in respect of any charge other than a royalty to the Court of Queen's Bench. Lastly, the power of Lieutenant Governor in Council to make regulations, especially those concerning the granting and administration of Crown dispositions and royalties, was expanded by this amendment. 


\section{b. The Freehold Oil and Gas Production Tax $\mathrm{Act}^{24}$}

The Freehold Oil and Gas Production Tax Act was amended by The Freehold Oil and Gas Production Tax Amendment Act, 1995. ${ }^{25}$ The definitions of "drainage unit," "gas" and "oil" were revised to be more precise and a definition of "zone" was added.

The main substantive change was the addition of provisions relating to the collection of taxes. If a taxpayer owes any taxes, interest or penalties under the Act or the regulations and has not appealed its liability or has acknowledged its liability, then once the amount owing becomes overdue, the Minister of Energy and Mines may file a certificate with the Court of Queen's Bench stating the amount of the debt. A registered certificate has the same force and effect as a judgment of the Court of Queen's Bench and the minister may issue a garnishee summons to any third party indebted to the taxpayer.

The Act was also amended to revise the authority of Lieutenant Governor in Council to make regulations in respect of the prices to be used to calculate the amount of tax payable under the $A c t$.

\section{Regulations}

a. The Crown Minerals Act

The Petroleum and Natural Gas Amendment Regulations, $1995^{26}$

This amending regulation adds new provisions to The Petroleum and Natural Gas Regulations, $1969^{27}$ for obtaining special exploratory permits and converting such permits to leases within the area known as the "Special Exploration Area." This area covers those portions of Saskatchewan that are not traditionally oil or gas producing areas. Permits will only be issued up to June 30, 1997.

Permits can be acquired on "permit lands" in a manner similar to other lands, although no permit lands within forty kilometres of any well cased for production can be advertised for disposition. Bids on permit lands must specify the amount of money the bidder will spend on eligible work on the permit lands for the first two years of the five-year term of the permit. The permit grants the right to explore for oil and gas on the permit lands.

Under a permit, a permittee is obligated to pay rent, drill a minimum of one well per permit, or two wells if the permit encompasses 100,000 hectares or more, and expend, on petroleum and natural gas exploration, a minimum of $\$ 2$ per hectare per annum for each of the first two years of the permit and a minimum of $\$ 4$ per hectare per annum for each of the last three years of the permit. A deposit is also required in respect of 
yearly expenditures and, if the permittee does not expend the minimum annual amount, the permittee may be allowed to make a non-refundable cash payment to maintain the permit in good standing.

Where a well which has been drilled on permit lands results in a commercial discovery of oil or gas, then the permittee may select a number of lease blocks from the permit lands that include the discovery well and that meet the size requirements prescribed in the regulations.

\section{b. The Freehold Oil and Gas Production Tax Act \\ The Freehold Oil and Gas Production Tax Regulations, $1995^{28}$}

These new regulations replace The Freehold Oil and Gas Production Tax Regulations, $1983^{29}$ and are effective retroactively to January 1,1994 . While a detailed discussion of these regulations is beyond the scope of this article, the freehold oil production tax is substituted with a conventional oil production tax including certain conventional oil production and gas production incentives.

\section{c. The Oil and Gas Conservation $\mathrm{Act}^{30}$ \\ The Oil and Gas Conservation Amendment Regulations, $1995^{31}$}

This regulation amends The Oil and Gas Conservation Regulations, $1985^{32}$ by reducing drilling restrictions near subsurface mines. Previously, no person could drill a well within an area under a potash disposition without giving notice to the Minister of Energy and Mines and the holder of the potash disposition who each had a right to object to such drilling. The restriction has now been limited to areas designated by the minister as a "potash restricted drilling area." The notice provision has been replaced with an obligation to obtain the consent of the minister and the potash disposition holder prior to the drilling of a well. The restriction relating to non-potash subsurface mines has been removed.

\section{Information Circulars}

\section{a. Information Circular PNG95IC01}

The Saskatchewan Department of Energy and Mines prepared this Information Circular in October 1995 to explain the pricing options available to all Crown royalty and freehold production taxpayers for determining the wellhead value of natural gas for royalty and tax purposes effective January 1,1996 . The pricing options are the Provincial Average Gas Price ("PGP") or the Operator Average Gas Price ("OGP"). 
Once a party chooses the PGP option, it is no longer qualified to use the OGP option. Elections were required to be made by January 15, 1996.

If a working interest owner becomes a new operator after December 31, 1995, it must provide the Department of Energy and Mines with notice specifying its preferred pricing option and a list of its current associated corporations. All associated corporations must elect to use the same pricing option.

The necessary amendments to The Crown Oil and Gas Royalty Regulations ${ }^{33}$ and The Freehold Gas Production Tax Regulations, 1995 to institute the foregoing changes have not yet been implemented. They are expected to be implemented by the fall of 1996 and will be retroactive to January 1, 1996.

\section{BRITISH COLUMBIA LEGISLATION}

\section{Regulations}

\section{a. Environmental Assessment $\mathrm{Act}^{34}$}

\section{(i) Environmental Assessment Reviewable Projects Regulation ${ }^{35}$}

This regulation brought the Environmental Assessment Act into force effective June 30, 1995, except for s. 94, and created the Environmental Assessment Reviewable Projects Regulation. Part 3 of this regulation deals with "Energy Projects."

The construction of a new energy storage facility is a reviewable project if it is capable of storing an energy resource yielding three petajoules ("PJ") or more by combustion. A modification of an existing facility is reviewable if the modification will result in the facility's capability exceeding the three PJ threshold. Neither the replacement of project components solely for maintenance purposes nor the development or use of naturally occurring underground reservoirs in the western Canadian sedimentary basin of northeast British Columbia is a reviewable project under the regulation.

The construction of any new facility that is an energy use project is a reviewable project. An energy use project is a plant facility or work designed to use, convert or process an energy resource at the rate of at least three PJ per annum. Modification of an existing facility is also reviewable if the modification results in an increase in the rate of use, conversion or processing which exceeds the three PJ threshold. An energy resource is deemed to be used, converted or processed at the rate of over three PJ per annum if it is of a quantity capable of yielding that amount by combustion. 
If a new transmission pipeline is constructed which has the capacity to transport an energy resource that can yield sixteen PJ or more of energy by combustion, it is a reviewable project. A transmission pipeline includes compression or pumping facilities and other related equipment but does not include flow lines, gathering lines or distribution lines. Modification of existing facilities will be reviewable if the modification results in the sixteen PJ threshold being exceeded or the addition of a new compressor or pumping facility. The replacement of pipe solely for maintenance or repair is not a reviewable modification.

The construction of a new platform, artificial island or other work, including associated facilities, are reviewable projects if such works are intended for exploration or production of oil and natural gas from the foreshore or submerged land along a marine coast or from an offshore site located in salt water.

\section{(ii) Transition Regulation ${ }^{36}$}

Projects that are the subject of a proposal dated on or after June 30, 1995 are reviewable under the Environmental Assessment Act. Projects that have been substantially started before June 30,1995 or that are the subject of proposals dated before June 30, 1995 to construct new facilities or modify existing ones and that fall within the prescribed classes are not reviewable under the Environmental Assessment Act. The prescribed classes include all of the projects described in the immediately preceding regulation, except offshore oil and gas facilities.

\section{REGULATORY DEVELOPMENTS}

\section{A. FEDERAL}

\section{National Energy Board}

a. Decisions

(i) Westcoast Energy Inc. South Mainline and Fort Nelson Mainline Expansions ${ }^{37}$

Westcoast Energy Inc. ("Westcoast") filed two applications to the NEB for approval to construct approximately $\$ 107$ million of additional pipeline loops to its mainline pipeline. The NEB approved the applications in a rare decision from the bench.

This hearing was the first convened by the NEB which applied the provisions of the Canadian Environmental Assessment Act. ${ }^{38}$ The CEAA requires a responsible authority such as the NEB to conduct an environmental assessment of a project as early as

37 In the Matter of Westcoast Energy Inc. Applications for the Construction of Looping on its Southern Mainline and Fort Nelson Mainline dated 19 June 1995 (June 1995), No. GH-2-95 (NEB) [hereinafter GH-2-95]. 
possible and before irrevocable decisions are taken with respect to a project. The assessment requirement operates as a condition precedent to the exercise of a regulatory power such as that contained in s. 58 of the NEB Act, which allows the NEB to grant an exemption from the requirement for a company to obtain a certificate of public convenience and necessity for certain types of facilities.

The NEB prepared a screening report respecting the possible environmental impact of each of Westcoast's applications. The screening reports were prepared by the NEB pursuant to s. 18(1)(b) of the CEAA. The NEB determined that public participation in the environmental assessment process conducted pursuant to the $C E A A$ was appropriate in the circumstances of this case. Subsection 18(3) of the $C E A A$ requires that the public be given notice of and an opportunity to examine and comment on the screening reports once a decision is made that public participation in the environmental assessment process is appropriate. The NEB met this requirement by releasing the screening reports at the commencement of the hearing which only lasted four days.

During the hearing, the NEB heard evidence related to environmental matters primarily from the West Moberly First Nations. Evidence which was presented included the potential impact on wildlife resulting from the pipeline construction. While the NEB felt that Westcoast should establish a more meaningful consultation process with the West Moberly First Nations, it concluded that the project would not result in significant or long-term impacts on hunting, fishing and other traditional activities.

The NEB was required to reach specific conclusions with respect to the requirements of the $C E A A$ and decided that:

(1) public concerns did not warrant a reference to a mediator or a review panel; and

(2) taking into account the implementation of mitigation measures that were discussed at the hearing, the project was not likely to cause significant adverse environmental effects.

Based on these conclusions the NEB determined that it could exercise any power or perform any duty or function conferred upon it by the $N E B$ Act.

In order to demonstrate the need for the applied-for facilities Westcoast had provided a ten-year macro forecast of gas deliveries to domestic and export markets which have access to gas off the Westcoast system. Westcoast also had executed ten-year firm service agreements with its expansion shippers. While most of these shippers provided information on the likely downstream purchasers of their gas or the likely markets to be served, no specific customers were identified. However, the NEB was satisfied that the ten-year firm service agreements, when coupled with Westcoast's macro demand forecast, provided a reasonable assurance that the applied-for facilities would be used and useful, and that the associated demand charges would be paid. It is noteworthy that the NEB recognized that "the gas marketplace continues to evolve in such a manner 
that does not allow all expansion shippers to have readily identifiable markets for future volumes associated with facilities which have yet to be built." ${ }^{39}$

The NEB approved Westcoast's applications but denied the West Moberly First Nations' request for costs on the basis that the NEB had no authority to award costs under either the NEB Act or the CEAA. The West Moberly First Nations' application for leave to appeal the NEB's decision was dismissed by the Federal Court of Appeal. They subsequently applied for leave to appeal the Supreme Court of Canada. ${ }^{40}$ The West Moberly First Nations' request for leave relates to the proper scope of the environmental assessment by the NEB under the $C E A A$ and the effect of the $C E A A$ on the fiduciary duty of Crown agents to protect aboriginal and treaty rights.

\section{(ii) TransCanada PipeLines Limited 1996-97 Facilities ${ }^{41}$}

TransCanada PipeLines Limited ("TCPL") applied to the NEB for approval to construct approximately $\$ 489$ million of additional pipeline loops and compression facilities in order to accommodate increased domestic and export requirements scheduled to commence on November 1, 1996. The NEB carried out an environmental screening of the application following the oral portion of this hearing. The NEB attempted to ensure that there was no duplication in satisfying the requirements of the $C E A A$ and the NEB's own regulatory mandate to consider environmental and directly related social effects of the application under Part III of the NEB Act. The NEB determined that TCPL's application should be approved, and pursuant to s. 20(1)(a) of the CEAA it decided that the project was not likely to cause significant adverse environmental effects.

In this decision, the NEB indicated that it had some concerns respecting Coastal Gas Marketing Company's gas supply arrangements made with Morgan Hydrocarbons Inc. and the gas supply information which was supplied in connection with this sale. The NEB did not deny TCPL's application on this basis as these matters were to be examined further in the GH-4-95 gas export licence hearing. ${ }^{42}$

In its discussion on land matters, the NEB referred to s. 112 of the NEB Act which regulates all excavation activity within thirty metres of a pipeline right-of-way. Under the National Energy Board Pipeline Crossing Regulations Part $I{ }^{43}$ if a contractor, facility owner or individual cannot obtain prior permission from the pipeline company, then approval from the NEB must be obtained before any excavation or construction activity is carried out on this setback area. The NEB noted that the Crossing Regulations have the power to affect all landowners within thirty metres of a pipeline, whether or not the landowner has granted a pipeline easement. Accordingly, the NEB

Supra note 37 at 4.

In June 1996, the West Moberly First Nations' application for leave to appeal to the Supreme Court of Canada was dismissed.

In the Matter of TransCanada PipeLines Ltd. Application for 1996 and 1997 Facilities dated 18 April, 1995, as amended (November 1995), No. GH-3-95 (NEB).

Infra note 62.

SOR/88-528 [hereinafter Crossing Regulations]. 
indicated that it expected TCPL to serve written notice to all potential landowners identifying the requirements of both s. 112 and the Crossing Regulations during its service of land acquisition documentation.

\section{(iii) Novagas Clearinghouse Pipelines Ltd. Pesh Creek Pipeline ${ }^{44}$}

Novagas Clearinghouse Pipelines Ltd. ("NCPL") applied to the NEB seeking approval for a sixteen and one half kilometre natural gas pipeline ("Pesh Creek Pipeline"). This pipeline would transport gas from a proposed separation, compression and metering facility in northeastern British Columbia ("Peggo Facility") to a proposed NOVA Gas Transmission Ltd. ("NGTL") metering facility in northwestern Alberta. The Pesh Creek Pipeline was to cost $\$ 3$ million. All associated equipment for the operation of the Pesh Creek Pipeline including separation, compression and metering facilities, mainline valves and pressure-relieving devices were to be located on the upstream and downstream connecting facilities. The upstream connecting facilities, all of which were located in British Columbia, consisted of the Peggo Facility, a sixty-five kilometre long gathering pipeline to the Midwinter field, and gathering pipelines to the Peggo, Tooga and Helmet fields. The downstream connecting facilities, all of which were located in Alberta, included the NGTL metering facility and eighty-six kilometres of NGTL pipeline to connect that metering facility to the nearest point on the existing NGTL system.

NCPL had applied pursuant to s. 58 of the NEB ACt for an exemption from the requirement to obtain a certificate of public convenience and necessity for the Pesh Creek Pipeline. Section 58 allows for an exemption to be made for pipelines not exceeding forty kilometres in length.

Prior to the commencement of the hearing, Westcoast advised the NEB that it considered the Pesh Creek Pipeline to be part of a larger project which included both the upstream and the downstream connecting facilities. As all the facilities would exceed forty kilometres in length, Westcoast argued that the s. 58 exemption was not applicable and that the NCPL application should be considered under ss. 52 and 24 of the NEB Act.

After considering the comments of interested parties, the NEB decided on January 12,1996 to refer the question of its jurisdiction over the upstream and downstream connecting facilities to the Federal Court of Appeal. NCPL then requested that the NEB review its decision to make the reference but the NEB denied the review request. An oral hearing on NCPL's Pesh Creek Pipeline application was held on January 19 and 20, 1996.

The NEB, by way of a letter dated January 22, 1996 approved NCPL's application. After carrying out an environmental screening the NEB determined that the NCPL project was not likely to cause significant adverse environmental effects. 
At the hearing, Westcoast had again argued that the NEB did not have jurisdiction and requested that the NEB adjourn the hearing of NCPL's application pending determination of the jurisdictional issue which had been referred to the Federal Court of Appeal. Alternatively, Westcoast asked the NEB to dismiss the application as it had done in the GH-1-92 proceeding in respect of the Altamont pipeline project which also involved connecting upstream facilities which were not proposed to be subject to NEB jurisdiction. Westcoast indicated that the jurisdictional reference would be rendered academic if the NEB approved the Pesh Creek Pipeline as the pipeline would have been constructed by the time the reference reached the Federal Court of Appeal. The NEB rejected Westcoast's arguments and concluded that as the applied-for facilities were less than forty kilometres in length it had jurisdiction. It indicated that the scope of the NEB's jurisdiction over connecting facilities was a matter of legal debate and uncertainty and was the subject of two pending appeals of previous decisions of the NEB and two references by the NEB to the Federal Court of Appeal. Given these circumstances the NEB felt that the issue of jurisdiction over the connecting upstream and downstream facilities should remain separate and distinct from the issue of the applied-for facilities. The NEB also noted that both the upstream and the downstream connecting facilities had already received provincial approvals for their construction and operation. ${ }^{45}$

The Pesh Creek Pipeline had a design transportation capacity of $170010^{3} \mathrm{~m}^{3} / \mathrm{d}(60$ MMcf/d) but NCPL had only entered into transportation agreements for $70810^{3} \mathrm{~m}^{3} / \mathrm{d}$ (25 MMcf/d) to $85010^{3} \mathrm{~m}^{3} / \mathrm{d}(30 \mathrm{MMcf} / \mathrm{d})$ of firm service and $14210^{3} \mathrm{~m}^{3} / \mathrm{d}(5 \mathrm{MMcf} / \mathrm{d})$ of interruptible service. The transportation agreements had initial minimum terms of five years and upon notice from the shipper could be extended for additional two-year periods. NCPL indicated that it was actively negotiating with other potential shippers but acknowledged that it was assuming a degree of risk associated with the pipeline being under-subscribed for an initial period. The NEB was satisfied that market arrangements are or would be in place to ensure that these facilities would be utilized at a reasonable level over their economic life.

NCPL filed copies of its transportation agreements which indicated that the transportation fee for 1996 of $\$ 0.12 / \mathrm{mcf}$ was based on the recovery of estimated annual operating costs and a portion of return on capital. The transportation fee was to be indexed and adjusted annually for changes in the Canadian Consumer Price Index. The transportation agreements also contemplated adjustments in the transportation fee for increased usage of the pipeline by new shippers. The NEB found this toll methodology to be acceptable as all parties had agreed to the terms of the transportation agreements, the transportation fee covered the pipeline's operating costs and contributed to return on capital and other shippers were not precluded from shipping gas on the proposed pipeline. NCPL was directed to file all formal transportation agreements with the NEB, or alternatively NCPL could file a general tariff outlining its terms and conditions pursuant to s. 60(1)(a) of the NEB Act. In determining that the project was economically feasible, the NEB relied on the fact that the contractual arrangements 
demonstrated that the parties found the economics of the Pesh Creek Pipeline project attractive enough to proceed.

Westcoast had also identified some of the problems it faced if projects such as the Pesh Creek Pipeline were approved. In particular it was concerned about the appropriateness of the one-year term of its service contracts with a six-month renewal right, which would allow a shipper to easily abandon the Westcoast system in favour of a bypass alternative. This could potentially leave Westcoast and its remaining customers exposed to escalating service costs. The NEB determined that these policy issues raised by Westcoast were beyond the scope of the GH-1-96 ${ }^{46}$ proceeding.

On February 21, 1996 Westcoast applied to the Federal Court of Appeal for leave to appeal the GH-1-96 decision.

Subsequent to the release of the GH-1-96 decision the Federal Court of Appeal issued its decisions on the Westcoast Aitken Creek appeal, the Grizzly Valley reference and the Consumers' Gas Company Ltd. Ottawa East Pipeline reference. In light of the decision of the Federal Court of Appeal, certain parties requested that the NEB discontinue its reference relating to the upstream and downstream connecting facilities to the Pesh Creek Pipeline. ${ }^{47}$

\section{(iv) Westcoast Energy Inc. Aitken Creek Facilities ${ }^{48}$}

As discussed in last year's legislative and regulatory developments article, ${ }^{49}$ the NEB dismissed Westcoast's 1994 application for a certificate of public convenience and necessity for a new gas plant to be located at Aitken Creek and for an expansion of Westcoast's Fort St. John gathering system. A majority of the NEB panel determined that the NEB did not have jurisdiction over these facilities. The majority's decision was based on a finding that the gathering and processing activities constituted an undertaking which was distinct from Westcoast's mainline transmission undertaking and thus not subject to federal jurisdiction. Westcoast appealed this decision to the Federal Court of Appeal and on February 9, 1996 the Court determined that the NEB did in fact have jurisdiction. ${ }^{50}$ The Federal Court of Appeal returned the matter to the NEB for a decision on the merits of the application. On April 3, 1996 BC Gas Utility Ltd. ("BC Gas") applied to the Supreme Court of Canada for leave to appeal the decision of the Federal Court of Appeal on the issue of the NEB's jurisdiction.

As a result of the ruling of the Federal Court of Appeal, the NEB proceeded to consider Westcoast's application and on March 4, 1996 the NEB approved the appliedfor facilities. However, as a result of changes in the marketplace since the initial May

Supra note 44.

On June 14, 1996, the NEB advised parties that it would proceed with the reference.

In the Matter of Westcoast Energy Inc. Application dated 6 October 1994 for the Fort St. John Expansion Project (May 1995), No. GH-5-94 (NEB) [hereinafter GH-5-94].

K.M. Miller et al., "Recent Legislative, Regulatory and Environmental Developments of Interest to Oil and Gas Lawyers" (1995) 33 Alta. L. Rev. 738.

Westcoast Energy Inc. v. Canada (National Energy Board) (1996), 134 D.L.R. (4th) 114 (F.C.A.). 
26, 1995 denial, Westcoast has subsequently advised the NEB that it will not proceed with the construction of either the Aitken Creek plant or the expansion of its Fort St. John gathering system.

The press release from the NEB which accompanied the GH-5-94 decision is interesting in that it indicates that the NEB was aware of discussions as to possible alternative approaches to the economic regulation of Westcoast's gathering and processing facilities. The NEB indicated that it "would be receptive to examining proposals for regulatory alternatives which might be brought before it, possibly as a result of settlement negotiations between Westcoast's transmission division and the stakeholders in its regulated business." ${ }^{\mathrm{II}}$

The GH-5-94 decision remains important even though the Aitken Creek facilities will not be constructed. As with the GH-2-95 ${ }^{52}$ Westcoast mainline expansion, the NEB did not find the lack of information on the specific markets proposed to be served by the incremental processed gas volumes to be of any significance. The NEB again relied on Westcoast's overall macro market assessments to ensure that the applied-for facilities would be used and useful over their economic life. The NEB was also not concerned that Westcoast's mainline capacity might be inadequate to transport the volumes resulting from an increase in processing capacity as there was a shorter lead time required for mainline expansions than for gathering and processing facilities. The NEB indicated that by executing firm processing agreements the producers were acknowledging their responsibility to arrange for appropriate downstream transportation service.

Westcoast had requested that the tolls for the services to be provided through the proposed facilities be determined on a rolled-in basis. BC Gas and the Canadian Council of Forest Industries ("COFI") had advocated a stand-alone toll design. The NEB determined that rolled-in tolling would be appropriate. The NEB appeared to rely heavily on the fact that, as a result of the configuration of the new facilities, the existing Westcoast McMahon plant and the Aitken Creek plant would be operationally integrated and therefore the Aitken Creek plant would essentially be an expansion of the functions of the McMahon plant rather than a discrete new facility constructed for the purpose of processing new gas supplies. Westcoast had relied on portions of the NEB's 1989 TransCanada PipeLines Limited GH-5-893 ${ }^{53}$ decision in order to support its rolled-in position. In the GH-4-94 $4^{54}$ decision, the NEB commented that although the NEB supported the principles set forth in the GH-5-89 decision, the NEB believed that the appropriateness of a tolling methodology was a matter that was project specific and that every application had to be assessed independently.

National Energy Board, News Release 96/13, "NEB Approves Westcoast Energy Inc.'s Fort St. John Expansion Application" (4 March 1996).

32 $\quad$ Supra note 37

33 In the Matter of TransCanada Pipeline Lid., Application dated 29 June 1989 (November 1990 and April 1991), No. GH-5-89-89 (NEB).

st In the Matter of Foothills Pipelines (Alta.) Lid., Application dated 30 June 1994 for the Wild Horse Pipeline Project (January 1995), No. GH-4-94 (NEB). 


\section{(v) Westcoast Energy Inc. Grizzly Valley Expansion Facilities ${ }^{5 s}$}

In November 1994 Westcoast applied for approval to construct a new gas plant at Tumbler Ridge, an expansion of its Grizzly Valley gathering system, and a new residue gas pipeline. In July 1995 Westcoast applied for approval to expand its existing Pine River gas plant rather than to construct the new plant at Tumbler Ridge, and for an expansion of its Grizzly Valley gathering system. On September 28, 1995 the NEB referred the question of its jurisdiction to consider Westcoast's application to the Federal Court of Appeal. The Court considered this reference along with Westcoast's appeal of the NEB's GH-5-94 $4^{56}$ decision on the Aitken Creek facilities and held that the NEB did have jurisdiction. As with the Aitken Creek facilities, a change in market circumstances has resulted in Westcoast advising the NEB that it will not proceed with its application for the Grizzly Valley expansion facilities at this time. ${ }^{57}$

\section{(iv) ISH Energy Ltd. Desan Pipeline ${ }^{58}$}

The NEB approved an application by ISH Energy Ltd. ("ISH") for a certificate of public convenience and necessity to construct a ninety-five kilometre pipeline (the "Desan Pipeline") from ISH's Desan field battery in northeastern British Columbia to a point in northwestern Alberta where the Desan Pipeline was to connect to the existing facilities of Interprovincial Pipe Line (NW) Ltd. The Desan Pipeline was a joint venture involving ISH and Westcoast Gas Services Inc. ("WGSI"). The selected pipeline size allowed for excess capacity which could be utilized if further development occurred in the vicinity of the proposed pipeline.

ISH and WGSI proposed to operate the Desan Pipeline in accordance with a Construction, Ownership and Operating Agreement. Each party was to have access to its own 50 percent of the pipeline capacity and pay 50 percent of the capital and operating costs. For the first ten years ISH had agreed to utilize WGSI's share and pay an "Excess Usage Charge" which provided WGSI with a suitable return on its investment. ISH stated that surplus capacity would be made available to any third party requesting capacity. The transportation fee for a third party would be set by commercial negotiation based on a consideration of both a reasonable return to the owners and the competitive rates on other pipelines. The NEB found that the proposed toll arrangements were reasonable given that the pipeline would be a Group 2 pipeline with its tolls and tariffs being regulated on a complaint basis. The NEB indicated that if third parties began utilizing the system, then ISH would be required to file a toll that was specified in a tariff pursuant to s. 60(1) of the NEB Act.

ss No hearing was held and no reasons for decision issued for this matter.

s6 Supra note 48.

57 "Producers Tell Westcoast Grizzly Valley Expansion No Longer Needed" Daily Oil Bulletin (23 February 1996).

58 In the Matter of ISH Energy Ltd. Application for Certificate of Public Convenience and Necessity, (September 1995), No. OHW-1-95 (NEB). 
(vii) Interprovincial Pipe Line Inc. and Westspur Pipe Line Company Inc. Expansion Facilities ${ }^{59}$

Interprovincial Pipe Line Inc. ("IPL") filed an application pursuant to s. 58 of the $N E B$ Act to add $\$ 86$ million of pumping units and tanks which would boost the delivery capacity of the existing IPL pipelines to Chicago by $18,900 \mathrm{~m}^{3} / \mathrm{d}(120,000 \mathrm{~b} / \mathrm{d})$. Westspur Pipe Line Company Inc. ("Westspur") filed an application to construct a new $\$ 5$ million, 33.4 kilometre pipeline known as the Portal Link Project which would increase the existing capacity of the Westspur system in southeastern Saskatchewan by $7950 \mathrm{~m}^{3} / \mathrm{d}(50,000 \mathrm{~b} / \mathrm{d})$. The NEB approved both applications and indicated that the rolled-in tolling treatment requested by IPL was appropriate. Both the capital and operating costs relating to the IPL project were considered to be non-routine adjustments under the terms of IPL's February 1995 incentive toll settlement agreement.

(viii) Brooklyn Navy Yard Cogeneration Partners L.P. \& Renaissance Energy Ltd. ${ }^{60}$

This was the first of two gas export licence hearings held in 1995. The NEB approved applications by Brooklyn Navy Yard Cogeneration Partners L.P. ("Navy Yard Partners") to extend an existing licence by five years from 2011 to 2016 and by Renaissance Energy Ltd. for a new licence until 2004. The NEB applied the usual Market-Based Procedure first implemented in 1987 and last modified in 1991. The NEB reviewed the upstream environmental effects associated with these two applications based on the necessary connection test discussed in last year's regulatory developments article. ${ }^{61}$ The hearing lasted seven days.

In its decision the NEB indicated that although it had no statutory or inherent authority to grant intervenor costs, the NEB had taken extraordinary steps to assist intervenors in order that they could participate fairly in the proceeding. The NEB also stated that in this hearing the normal procedural requirements were applied and that the extent of the latitude which the NEB had shown to intervenors in the GH-3-94 proceeding was not deemed to be appropriate. The NEB now expected intervenors to be more familiar with the NEB's procedures. Intervenors' preliminary motions were all rejected by the NEB. These motions included an application to find that an apprehension of bias existed on the part of the NEB, a request that an adjournment of the hearing be granted on the basis that the applicants had provided insufficient evidence, and an application for a ruling that the NEB not utilize the necessary connection test in connection with an evaluation of upstream environmental effects related to the applications.

In the Matter of Interprovincial PipeLine Inc. \& Westspur Pipeline Company Inc., Applications dated 7 September 1994 as amended for Expansion Facilities and Toll Methodology (January 1996), No. OHW-2-95 (NEB). Applications Pursuant to Part VI of the National Energy Board Act for Licences to Export Natural Gas (July 1995), No. GH-1-95 (NEB). 
The Market-Based Procedure includes an Export Impact Assessment ("EIA"). The purpose of an EIA is to allow the NEB to determine whether or not a proposed export is likely to cause Canadians difficulty in meeting their energy requirements at fair market prices. The NEB has prepared two EIAs with the latest being issued in December 1994. The 1994 EIA covers the period 1993 through 2010. The Navy Yard Partners' application was for an extension of exports until 2016 and it sought to extrapolate the trend line of the NEB's 1994 EIA after 2010. The intervenors sought to have the Navy Yard Partners' application dismissed on the basis that there was no EIA for the 2010 to 2016 period.

The NEB determined that, given the conclusion in its 1994 EIA that a high level of exports was sustainable to 2010 under a wide range of scenarios, it was likely that some level of exports would be sustainable beyond that year. Given that the currently authorized licensed volumes under all existing licences for the period beyond 2010 were small and that the quantity of gas requested by Navy Yard Partners for export was also very small, the NEB was satisfied that the export of the Navy Yard Partners' volumes would not cause difficulties for Canadians in meeting their future energy requirements at fair market prices during the 2010 to 2016 period.

\section{(ix) Volume 1 Altresco Pittsfield L.P., Crestar Energy, Enron Capital \& Trade Resources Corp. and Husky Oil Operations Ltd. ${ }^{62}$}

After a single day hearing the NEB approved three applications for new licences and an application by Husky Oil Operations Ltd. for a two year extension to an existing licence. In its application Enron Capital \& Trade Resources Corp. ("Enron") had requested that any licence issued to it not be conditioned so as to restrict the export to a single export point. Enron indicated that the market to be served would be Enron's overall corporate Unites States gas supply portfolio although it expected its primary market to be the U.S. Northeast. If no export point was specified Enron would have increased flexibility in its marketing activities. The NEB denied Enron's request and specified Iroquois, Ontario as the single point of export. That point appeared to be more reflective of the commercial arrangements underpinning the applied-for licence, especially Enron's TCPL transportation agreement.

\section{(x) Volume 2 Morgan Hydrocarbons Inc. and Coastal Gas Marketing Company ${ }^{63}$}

An application by Morgan Hydrocarbons Inc. ("Morgan") and Coastal Gas Marketing Company ("Coastal") for a new gas export licence was also heard at the one day GH-495 hearing. When it released Volume 1 of its decision on the remaining GH-4-95 applications, ${ }^{64}$ the NEB indicated that the Morgan/Coastal application was being held Applications Pursuant to Part VI of the National Energy Board Act for Licences to Export Natural Gas and, Husky Oil Operations Lid., Application Pursuant to Section 21 of the National Energy Board Act to amend a Licence to Export Natural Gas, vol. 1 (January 1996), No. GH-4-95 (NEB). In the Matter of Morgan Hydrocarbons Inc. and Coastal Gas Marketing Company Application, (January 1996), No. GH-4-95 (NEB). 
in abeyance pending receipt of further information. In a letter to Morgan and Coastal dated February 20, 1996 the NEB denied their application. Somewhat surprisingly, the NEB did not release this letter until April 1, 1996.

The denial of the Morgan/Coastal application should not be viewed as any change in the NEB's approach to gas export licence applications. Essentially, the application was denied because Morgan/Coastal refused to provide the NEB with certain requested information respecting Morgan's gas supply despite numerous requests for such information from the NEB.

The decision is helpful in that it discusses the NEB's requirements relating to the gas supply information which is necessary to support a gas export licence application. The NEB identified four types of gas supply: dedicated supply, non-dedicated supply or submitted supply, corporate pool supply and aggregator supply. Morgan/Coastal had relied on a non-dedicated or submitted supply which meant that they were relying on an identified list of pools in support of the gas export proposal, but the pools were identified simply to satisfy regulatory filing requirements and might not ultimately be the pools relied upon for the export sale. The NEB noted that with a non-dedicated supply, the real source of the gas supply was the corporate pool.

The NEB recognized that since the Market-Based Procedure was implemented, applicants for gas export licences have moved away from relying on contractually dedicated supply and that the NEB now normally received either a submitted supply or a corporate pool supply. The NEB referred to the National Energy Board Part VI Regulations ${ }^{65}$ and recognized that changes had occurred in the natural gas industry since those regulations went into force. However, the proposed new Part VI (Oil and Gas) Regulations ${ }^{66}$ still required an overall gas supply and demand balance for all firm commitments supported by the reserves submitted in support of an application.

Despite five requests from the NEB, Morgan/Coastal refused to provide an overall corporate supply and demand balance. The NEB felt that this information was required in order for it to make a decision and accordingly denied the application.

The impact of the denial on Morgan/Coastal did not affect the gas sale between these companies as the gas continued to flow under a short-term export order. Morgan/Coastal have filed a new application for a long-term export licence which will be heard this spring along with eight other applications. These applications are being dealt with by a written hearing rather than an oral hearing. 
In this decision the NEB approved a 5.6 percent increase in Westcoast's tolls for 1995. The NEB continued its global approach to assessing Westcoast's operating and maintenance costs and provided for an overall reduction in these costs of $\$ 3.4$ million. The NEB indicated that it was disappointed by the narrow scope of cross-examination by the intervenors at this hearing which had focused in on minor discretionary cost items rather than more important items. The NEB gave the example of the overall level of Westcoast's field operating costs where it felt that the intervenors would have some useful information to present to the NEB.

The NEB also approved certain modifications to Westcoast's General Terms and Conditions which would only require Westcoast to provide its shippers with contract demand credits during the summer shipping season when it delivered less than 90 percent of the shippers contract demand. Westcoast's proposal to remove its Queuing Procedures \& Access Criteria from its General Terms and Conditions and replace it with an Expansion Service Delivery Policy was also approved. The new policy contained several amendments to Westcoast's criteria for accepting applications for new service. A new Attrition Capacity Allocation Program was also approved for addition to Westcoast's General Terms and Conditions.

\section{(xii) Foothills Pipe Lines Ltd. Deferred Tax Drawdown ${ }^{68}$}

In 1992 the NEB had directed Foothills Pipe Lines Ltd. ("Foothills") to switch its methodology used in providing for income taxes in its tolls from the normalized method to the flow-through method. At the time Foothills' balance of deferred income taxes was $\$ 135.8$ million. In the RH-1-95 hearing the NEB considered how this balance should be drawn down and authorized a drawdown over a ten-year period on a straight line basis commencing January 1, 1996. The impact of this drawdown would usually be to reduce Foothills' tolls. However, the reduction was largely offset by a previously decided increase in Foothills' depreciation rate which also commenced on January 1, 1996.

The Canadian Association of Petroleum Producers ("CAPP") had requested that the NEB also examine the cost efficiencies of Foothills' operating arrangements for its various zones. The NEB concluded that these arrangements continue to be cost effective. 
(xiii) Phase 1 TransCanada PipeLines Limited Tariff Matters and FST ${ }^{69}$

In July 1995 TCPL filed an application to determine its tolls for 1996. Phase 1 of the hearing dealt with issues related to cash allocation, toll design and tariff matters. TCPL's tolls task force had reached agreement on twenty-one resolutions approving various amendments to TCPL's transportation tariff. The NEB approved the requested tariff changes as the agreement among the TCPL tolls task force members satisfied the NEB's August 23, 1994 Guidelines for Negotiated Settlements of Traffic, Tolls and Tariffs ("NEB Settlement Guidelines").

The Consumers' Gas Company Ltd., Union Gas Limited, CAPP, and TCPL had also reached an agreement respecting certain issues relating to TCPL's Firm Service Tendered service ("FST") but certain other interested parties had been excluded from participation in the process which led to the signing of the FST agreement. Accordingly, the NEB did not believe that the agreement satisfied the requirements of the NEB Settlement Guidelines and therefore addressed the merits of the changes to FST which had been agreed to.

On the merits the NEB approved TCPL's requested changes in the method of calculating the differential for FST service which resulted in a lower FST toll. The NEB also split the FST differential into an upstream and a downstream component. It had been requested to do so primarily because certain gas sales contracts in the industry had pricing provisions which had provided for a price increase equal to the amount of any upstream FST. In the previous year's RH-3-94 decision in respect to TCPL's 1995 tolls the NEB had not split out the FST differential into upstream and downstream components and there was some uncertainty as to the impact on the pricing provisions in those contracts.

In addressing its jurisdiction to make the FST differential split the NEB referred to its broad jurisdiction in respect of traffic, tolls and tariffs as set out in s. $\mathbf{5 9}$ of the $N E B$ $A c t$ and indicated that its decisions may properly affect private contractual rights provided that the impacts on contract arrangements are incidental to the NEB's exercise of its regulatory powers. As the identification of an FST differential split was a matter relating to TCPL's system flexibility it was also related to traffic, tolls and tariffs and thus was within the NEB's jurisdiction.

\section{(xiv) Phase 2 TransCanada PipeLines Limited Incentive Settlement Agreement ${ }^{70}$}

In December 1995 TCPL applied to the NEB for approval of a toll settlement agreement (the "Settlement Agreement") which would determine the net revenue requirement utilized by TCPL in the calculation of its tolls for the years 1996 through 1999. After a one day forum held by TCPL to present the Settlement Agreement and 
provide parties with an opportunity to question TCPL on it, the NEB approved the Settlement Agreement.

The formal Incentive Cost Recovery and Revenue Sharing Settlement had been approved by TCPL's tolls task force and no other party opposed the settlement. While the Settlement Agreement is a complex document some of its key business elements are:

(1) it covers a four-year period until December 31, 1999;

(2) the objectives of the Settlement Agreement were stated to be to minimize costs, maximize throughput, encourage efficiency gains, maintain or improve service quality and financial integrity and preserve firm shippers' flexibility and ability to effectively use their transportation contracts;

(3) that generally TCPL's expenses are divided into either an Incentive Cost Envelope or a Flow-Through Cost Envelope;

(4) the Incentive Cost Envelope is made up of five components: transportation by others costs, operations, maintenance and administration costs, gas related expenses, municipal and other taxes and NEB cost recovery expense;

(5) the Incentive Cost Envelope costs were fixed at a certain level for 1996 and will be reestablished each year based on the actual experienced costs in the preceding year, multiplied by a "net adjustment factor";

(6) any variances in actual Incentive Cost Envelope costs from the test year forecast of these costs are generally shared equally by TCPL and its shippers;

(7) the Flow-Through Cost Envelope includes return on rate base, income taxes, depreciation, foreign exchange costs and stress corrosion cracking costs;

(8) subject to a review and complaint procedure set out in the Settlement Agreement, all variances between the actual costs in the Flow-Through Cost Envelope and the corresponding test-year costs will flow directly to the cost of service for the next test year;

(9) other provisions in the Settlement Agreement cover complaints by shippers, TCPL's tolls task force review of cost adjustments and amounts of shared revenue, calculation of allocation units and tolls, reporting and filing requirements and audits; and

(10) toll design and tariff matters are not part of the Settlement Agreement. 
(xv) Trans Mountain Pipe Line Company Ltd. Toll Design and Incentive Toll Agreement ${ }^{71}$

In November 1995 Trans Mountain Pipe Line Company Ltd. ("Trans Mountain") advised the NEB that it had reached a settlement in principle with CAPP and its principal shippers with respect to its revenue requirement for 1995 and an incentive toll settlement for the years 1996 to 2000 .

The RH-3-95 decision addresses Trans Mountain's toll design for 1996. Trans Mountain had applied for a new methodology for calculating tankage use, costs and credits. Trans Mountain indicated that its system had evolved from simply a crude oil pipeline to one which now transported a number of products on a batch basis and its existing toll design no longer equitably allocated tankage costs to its system users in proportion to the benefits received. Trans Mountain's proposed recommendations included a roll-in of the costs of previously dedicated facilities and the establishment of a 25 percent tankage credit for shippers of directly injected and delivered throughput. Various intervenors objected to certain aspects of Trans Mountain's proposals. While the NEB was not totally convinced that there might not be better methods of determining the appropriate level of the tankage credit it nonetheless approved Trans Mountain's application.

The RHW-2-96 decision addresses Trans Mountain's incentive toll settlement agreement. This agreement had been negotiated with CAPP and Trans Mountain's principal shippers, Chevron Canada Limited ("Chevron"), Imperial Oil Limited, Shell Canada Limited and Petro-Canada Limited. Only Trans Mountain, Chevron and CAPP were signatories to the final agreement. Some of the key elements of the incentive toll settlement agreement are:

(1) it covers a five year period until December 31, 2000 with provisions to renew the agreement thereafter;

(2) the revenue requirement for 1996 was fixed;

(3) the revenue requirement for 1997 and thereafter will include:

(a) the previous years starting point increased by changes to the Consumer Price Index with a 1 percent minimum and a 5 percent maximum increase;

(b) the difference between the actual and the forecast tax expense for the previous year; 
(c) 80 percent of the variance in the previous year's transportation revenue from its forecast; and

(d) amounts associated with certain defined non-routine adjustments;

(4) positive variances relating to capacity enhancement activities, excess net income and increased new materials throughput are to be shared equally by Trans Mountain and its shippers; and

(5) the agreement requires renegotiation during the term on the occurrence of certain events including any downgrade in Trans Mountain's debt.

The NEB determined that the NEB Settlement Guidelines were met and approved Trans Mountain's incentive toll settlement.

(xvi) Westcoast Energy Inc. 1996 Tolls $^{72}$

In January 1996 Westcoast filed a settlement with the NEB in respect of its 1996 tolls. The settlement was reached with CAPP, COFI, BC Gas, the Export User Group, Can West Gas Supply Inc. and the Province of British Columbia. Key elements of the settlement agreement were:

(1) a reduction of Westcoast's 1996 revenue requirements from the applied-for amount of $\$ 552.7$ million to $\$ 509.7$ million;

(2) a lump sum reduction in Westcoast's operations and maintenance budget by $\$ 4$ million;

(3) a withdrawal of Westcoast's application to increase its depreciation rates;

(4) a reduction of Westcoast's capital program by approximately $\$ 26$ million; and

(5) Westcoast's agreement not to seek amendments to the renewal provisions of Westcoast's General Terms and Conditions in respect of various services.

The NEB applied the NEB Settlement Guidelines and approved the settlement as filed. 


\section{b. Joint Review Panel Decision}

Express Pipeline Project - Report of the Joint Review Panel of the National Energy Board and the Canadian Environmental Assessment Agency ${ }^{73}$

The Express Pipeline project ("Express Project") is a project which will construct a crude oil pipeline from Hardisty, Alberta to Casper, Wyoming. The Canadian portion of the project would consist of $\mathbf{4 3 5}$ kilometres of pipeline and associated terminaling, storage and pumping facilities at an estimated cost of $\$ 196$ million. The application for the Express Project met the criteria for a comprehensive study under the Comprehensive Study List Regulations ${ }^{74}$ issued pursuant to the CEAA. ${ }^{75}$ The NEB, under its authority under the $C E A A$, referred the Express Project to the Federal Minister of the Environment in order to harmonize the environmental assessment requirements and to avoid unnecessary duplication of public review processes.

On June 22, 1995 the NEB issued a hearing order which indicated that the NEB had requested approval from the Minister of the Environment for substitution of the NEB's hearing process for an environmental assessment by a review panel under the CEAA. This request ultimately resulted in an agreement between the NEB and the Minister of the Environment concerning the establishment of a joint review panel for the Express Project.

The joint review panel (the "Panel") consisted of two permanent members of the NEB and two individuals who were appointed by the minister. The Panel was struck to examine the environmental effects likely to result from the proposed construction and operation of the Express Project and to prepare a report setting out its findings, conclusions and recommendations. The two individuals appointed by the minister were appointed as part-time temporary members of the NEB in order that they would also have the authority to address matters within the NEB's jurisdiction under Part III of the NEB Act.

Pursuant to the agreement establishing the Panel, the factors to be considered in the environmental assessment of the Express Project included:

(1) the description and purpose of the project;

(2) alternative means of carrying out the project;

(3) a description of the environment;

(4) the environmental effects of the project, including cumulative effects;

(5) the significance of those effects;

(6) mitigation measures;

(7) the capacity of renewable resources that are likely to be significantly affected by the project to meet the needs of the present and those of the future; and

(8) comments from the public and government agencies. 
A public hearing with respect to the project was held from January 15 to March 7 , 1996. One of the first rulings that the Panel was required to make in the course of conducting its assessment was to define the scope of the project. Although the scope of the principal project was never in doubt, the definition of "accessory physical works" was the subject of considerable debate. In particular, the Panel had to interpret the proper meaning given to the words "upstream facilities that would need to be constructed to enable the principal project to proceed." In this regard the Panel held that such words should be interpreted to mean any new upstream physical works (not activities) that are required to be built to make possible the commencement of operation of the principal project. These upstream facilities will be minor or subservient in nature to the principal project and be interdependent with it. The Panel held that the CEAA did not contemplate that any upstream facilities that may be constructed during the life of the pipeline and are related to the oil that may eventually move on the pipeline would be within the scope of the project subject to assessment.

At the hearing a difference of opinion also arose with respect to the obligations of the Panel to consider alternatives under the CEAA. The applicant asserted that the obligation to consider alternatives referred to alternative means of carrying out the Express Project rather than alternatives to the Express Project. The Rocky Mountain Ecosystem Coalition asserted that the applicant was required to consider alternatives to the project. The Panel considered the wording contained in the agreement pursuant to which it was established and concluded that by using the words "alternative means of carrying out the Express Project," the Minister of the Environment had not asked the Panel to consider alternatives to the Express Project although she was free to do so under the $C E A A$. Alternative means could include different routes but not an entirely different project. Accordingly, the Panel found that it had not been given a mandate under the CEAA to consider the environmental effects of alternatives to the Express Project. However, the Panel did note that when considering the application pursuant to the NEB Act, the Panel must find the project to be in the public convenience and necessity and that the need for the project and the alternatives to the project were issues that may arise in that context.

The Panel issued a detailed report which contained forty-three conclusions and thirtynine recommendations. By a three to one majority decision the Panel was of the view that based on the applicant's proposed mitigation measures, the Panel's conclusions and with the incorporation of the Panel's recommendations, the proposed project was not likely to cause significant adverse environmental effects. The Panel recommended that the applicant be required to implement or cause to be implemented all of the policies, practices, Panel recommendations and procedures for the protection of the environment included or referred to in its application, its undertakings made to the Department of Fisheries and Oceans and Environment Canada, and adduced in evidence before the Panel during the proceedings. 
Some of the more significant conclusions and recommendations made by the majority were as follows:

(1) The Panel concluded that the applicant had not adequately addressed the concerns associated with its original May to August construction schedule and recommended that the applicant be required to comply with its August 1 to November 31 updated construction schedule for pipeline construction unless otherwise allowed by the Panel.

(2) With respect to routing, the Panel found that the applicant's approach to route selection was acceptable and that having considered alternative means to carry out the project including alternate routes, the Panel was of the view that the applied-for route was acceptable.

(3) The Panel approved the applicant's rationale for proposing an open cut crossing technique for the South Saskatchewan River.

(4) The Panel examined the cumulative effects of the project and was critical of the manner in which evidence relating to cumulative effects had been presented. However, it found that the project was not likely to result in significant adverse cumulative environmental effects.

In a strongly worded dissent, one of the members of the Panel recommended that the project not proceed. Dr. Glennis Lewis was unable to agree with the majority and came to the conclusion that the evidence produced by the applicant was inadequate from both a legal and scientific perspective to permit the Panel to determine whether or not the project will have significant adverse environmental effects in accordance with the $C E A A$. Dr. Lewis found that one has to know what the environmental effects or cumulative effects are or will be before mitigation of those effects can be properly considered and that the applicant did not follow the logical progression of first considering the project's effects, the cumulative effects and the significance of these effects in its environmental assessment prior to looking at mitigative measures. She found that in many important areas so much faith was placed in mitigation and reclamation measures that a thorough analysis of both the environmental effects and the cumulative environmental effects of the project were not undertaken. She found that in certain key areas there was no evidence at all from the applicant respecting the environmental effects of the project and in other cases there was some evidence but the methodologies used to arrive at the conclusions were suspect. In some areas, she found that there was ample evidence but the applicant drew the wrong conclusions from it. Dr. Lewis found that the applicant did not carry out an environmental assessment that would have put sufficient information before the Panel to enable it to fully consider what the environmental effects of the project would be and that the legal requirement of providing such information rested upon the applicant. In the result Dr. Lewis 
disagreed with the majority's findings, conclusions and recommendations and considered it would be wrong at law to recommend that the project proceed. ${ }^{76}$

\section{c. Public Inquiry \\ Stress Corrosion Cracking}

In August 1995 the NEB announced that it would hold a public inquiry into stress corrosion cracking ("SCC") on Canadian oil and gas pipelines. SCC involves a process which can result in the formation of cracks on the surface of a buried pipeline which, in severe cases, can result in the failure of the pipeline. TCPL had a pipeline rupture on its system north of Brandon, Manitoba on July 29, 1995 a portion of its pipeline which was not thought to be susceptible to SCC. This was the seventh line rupture on TCPL's system due to SCC since 1985. There have been thirteen failures on other Canadian pipeline systems attributed to SCC since 1977. The NEB had conducted a previous inquiry into SCC in 1993. The NEB called its inquiry into SCC pursuant to s. 15(1) of the NEB ACt and prepared a very detailed list of issues which would be considered during the inquiry. Prior to a public hearing which was held in April 1996 the NEB gathered information on the status of research on SCC and the experience of pipeline companies and other regulatory agencies. NEB representatives also met informally with residents and municipal officials in localities near the location of recent pipeline failures. The Canadian Energy Pipeline Association was an active participant at the SCC hearing and coordinated the input on this issue from its member companies.

The report of the inquiry has not been released as of May 31, 1996. ${ }^{77}$

\section{d. Guidelines}

\section{(i) Section 58 Streamlining Initiative}

The NEB revised streamlining Order XG/XO-100-94 on November 16,1995 . This order sets out certain types of facilities which are deemed to be exempt pursuant to $\mathrm{S}$. 58 of the NEB Act and accordingly no prior approval from the NEB is required. The revisions to this order were made to take into account the requirements of the CEAA and to allow for exemption of certain defined projects which will be implemented in a multi-year program.

\section{(ii) Memorandum of Guidance on Regulation of Group 2 Companies}

On December 6, 1995 the NEB issued an updated version of its Memorandum of Guidance on the regulation of Group 2 companies. The ten largest pipelines regulated by the NEB are classified as Group 1 companies with all remaining pipelines being classified as Group 2 companies. The Memorandum of Guidance sets out the extent of regulation for Group 2 companies. Schedule A sets out the minimum information 
requirements for the design, construction and operation of pipelines. Schedule B sets out the guidelines for the regulation of tolls and tariffs. Financial regulation of Group 2 companies is usually carried out on a complaint basis. If a complaint is received, the NEB will then require detailed information in support of a tariff. In February 1995 the NEB issued new Guidelines for Filing Requirements. The Memorandum of Guidance was revised to include references to these new Guidelines for Filing Requirements.

\section{B. ALBERTA}

1. Alberta Energy and Utilities Board

\section{a. Decisions}

(i) Beau Canada Exploration Limited Application to Construct and Operate a Natural Gas Pipeline in the Gilby Area ${ }^{78}$

Beau Canada Exploration Limited ("Beau") applied to construct approximately ten kilometres of pipeline to tie two existing gas wells into Beau's Gilby gas plant. The application was opposed by Paragon Petroleum Corporation ("Paragon"). Paragon believed that the wells should be tied into its pipeline. Although the Beau proposal would involve the construction of five kilometres more pipeline than what would be required if the wells were tied into the Paragon pipeline, Beau submitted that the Paragon pipeline was incapable of transporting the additional production without additional compression. The EUB approved Beau's application.

The EUB stated that all oil and gas operators, before applying to the EUB for a new pipeline development, must consider existing pipelines that afford a reasonable alternative to new construction in order to preclude unnecessary development of new pipelines and thereby minimize social and environmental impacts. The EUB found that both alternatives would have some environmental impacts. Construction of the Paragon option would require less surface disturbance but would require construction of a compressor station with its own associated potential surface and noise impacts. In this case the EUB noted that no landowner or occupant objections were received regarding the Beau application whereas it was unknown whether or not the Paragon option would be contested by area residents. The EUB accepted Beau's position that the use of the Paragon pipeline could reduce its flexibility in the development of Beau's reserves in the region and that while the expansion of the Paragon pipeline did appear to represent a significant economic advantage to Paragon it was less likely that Beau would receive any economic benefit. Overall, the EUB did not find that there were any significant economic impacts from Beau's proposal that would have an adverse effect on the public. The EUB determined that in the absence of any public, economic, social or environmental issues, it was not prepared to intervene in normal business decisions made in the competitive marketplace. 
(ii) CU Gas Limited and Federated Pipe Lines Ltd.

Applications for a Sweet Gas Facility and Associated Pipelines ${ }^{79}$

CU Gas Limited ("CU") requested approval to construct and operate a sweet gas processing plant just northwest of Edmonton. Federated Pipe Lines Ltd. applied for approval to construct pipelines connecting the new plant to its system. The CU application was opposed by a coalition of area residents. The issues involved in CU's application included the suitability and effectiveness of CU's public consultation process, the need and justification for the facility, the site selection process, the impacts of the proposed facility and the suitability of the proposed site.

The EUB was critical of the public consultation program conducted by $\mathrm{CU}$ and determined that in effect CU had initially conducted a public "information" program rather than a public "consultation" program. The EUB emphasized that meaningful public consultation is an expected and very important element in the development of new energy resource projects. To make a public consultation program effective, the EUB indicated that the applicant must initiate it as early as possible in the process, allowing opportunity for public input into the decision-making criteria and consideration of concerns with the site selection process and any other issues important to the community. The EUB also recognized that the size and the complexity of a project and the nature of the area are factors which will influence how a public consultation program is designed. The larger and more complex the project is and the more dense the population of the area surrounding the proposed site is, the greater the requirement for public consultation. A key factor in determining the appropriate level of the public consultation in the project is the apparent interest in it by the community as a whole. The EUB found that in this case, CU had initially misjudged the level of interest and thus failed to meet the community's expectations for involvement. Although the EUB felt that CU's public consultation program could have been substantially better than it was, the EUB was not prepared to deny the application or defer a decision on the application for that reason alone. However, the EUB stated that it "wishes to remind industry that it has begun to change its approach to regulation. Once this change is fully implemented, its expectation will be that industry understands, respects and meets or exceeds regulations and standards including those related to public consultation. Failure to meet these requirements could result in harsher consequences than in the past." 80 Accordingly, it is conceivable that the EUB may in future cases deny an application where the public consultation process was seriously flawed.

In approving the project the EUB determined that the natural gas resource would be used more efficiently through the recovery of the hydrocarbon liquids rather than burning these liquids for fuel. Recovery would allow benefits to accrue to the province through increased royalties and result in a more efficient use by upgrading a nonrenewable resource. There was some discussion with respect to the alternative of of Villeneuve, Alberta; CU Gas Limited and Federated Pipelines Ltd. (15 December 1995), No. D95-14 (EUB). 
expanding existing facilities. However, the EUB stated that in order for this alternative to be accepted it would need to provide a greater economic return than the proposed new plant as the expansion would be a much more complex operation. Since the EUB did not believe that the use of existing facilities presented a clearly superior economic alternative or one that would substantially reduce the overall impacts of this scheme, CU's application was approved. The EUB held that on an overall basis the site selection by $\mathrm{CU}$ would be the most suitable location for the plant and that the project could proceed with minimal impact on the environment and the community.

\section{(iii) Petro-Canada Common Carrier Order Two Creek Field ${ }^{81}$}

Petro-Canada applied under s. 37 of the Oil and Gas Conservation $A c t^{82}$ for an order declaring Paramount Resources Ltd. ("Paramount") a common carrier of gas produced from the Two Creek Viking A Pool through pipelines owned by Paramount from Petro-Canada's wells to a Paramount gas processing facility. This application was first considered by an EUB panel of examiners.

The examiners set out the following requirements for a common carrier order which an applicant for a common carrier order would be required to satisfactorily demonstrate:

(1) that producible reserves are available for transportation through an existing pipeline;

(2) there is a reasonable expectation of a market for the substance which is proposed to be transported by the common carrier operation;

(3) the applicant could not make reasonable arrangements to use the existing pipeline; and

(4) the proposed common carrier operation is either the only economically feasible way or clearly the most practical way to transport the substance in question, or is clearly superior environmentally.

There was no dispute about the fact that Petro-Canada had producible reserves available for transportation through the existing Paramount pipeline, nor was there any question that Petro-Canada had a market for the gas produced from the pool in question.

Petro-Canada submitted that approximately 26 percent of the reserves in the subject pool were held by Petro-Canada and that a common carrier order was required to mitigate drainage of its reserves. Although Petro-Canada had access to Paramount's pipeline facilities under an interim agreement, Paramount had limited the volume produced from Petro-Canada's wells to about 16 percent of total pool production. As 
a result, Petro-Canada was not receiving what it considered to be its equitable share of pool reserves and was suffering drainage.

The examiners were of the view that Petro-Canada's reserves were being drained in an inequitable manner and that negotiations for a mutually satisfactory arrangement respecting Petro-Canada's use of Paramount's pipeline were at an impasse. They found that neither party conducted meaningful or sincere negotiations, but stated that this would not be reason enough to deny the application for a common carrier order since in this case drainage was occurring and action needed to be initiated to address this problem. Since the parties were unlikely to reach a voluntary agreement the examiner's recommendation was to provide Petro-Canada with firm access to the pipeline for an equitable share of the pool reserves. The examiners found that the alternative of constructing new facilities which would duplicate the existing pipeline was impractical since such facilities would in all likelihood be under-utilized in a relatively short period of time. They also recognized that new construction would cause an environmental impact that could be avoided by using the existing pipeline and therefore concluded that the existing pipeline represented the most practical and efficient means of transporting Petro-Canada's gas. The examiners felt that a finding on allocation would assist in giving effect to the common carrier order and that it would be appropriate to allocate to Petro-Canada sufficient pipeline capacity to enable it to produce 23 percent of total pool production.

The recommendations contained in the examiners' report were considered by the EUB. While the EUB declared Paramount a common carrier of gas it did not accept the examiners' recommendation to allocate a portion of pool production to Petro-Canada and stated that if an agreement could not be reached on this issue by the parties, an application for rateable take could be made.

(iv) NGTL Applications to Construct and Operate Natural Gas Pipelines in the Zama/Shekilie $\mathrm{Area}^{83}$

NGTL applied for approval to construct and operate pipelines in the northwestern corner of Alberta which would connect to upstream facilities which would transport gas from northeastern British Columbia.

At the outset of the hearing Westcoast argued that the EUB did not have jurisdiction to consider the NGTL applications and that the hearing should be adjourned. It submitted that NGTL's proposed facilities were related and integral to facilities concurrently proposed by Novagas Clearinghouse Ltd. ("NCL") and NCPL to the British Columbia Ministry of Municipal Affairs and the NEB respectively. Westcoast stated that these proposals were inter-provincial in nature and should be considered as one federal undertaking within the jurisdiction of the NEB. NGTL did not agree with Westcoast's characterization that NGTL's proposed facilities were inter-provincial in nature and stated that its proposed facilities were within Alberta and should be 
considered as a separate entity from those of NCL and NCPL. The EUB noted that, with the exception of a six kilometre lateral to the border, all of the pipeline facilities applied for by NGTL had been in NGTL's annual plans since June 1994. The EUB accepted that the proposed facilities were necessary for intra-provincial development of the province's resources and essentially were an extension of NGTL's gathering system in Alberta. It accordingly held that it had the necessary jurisdiction as well as responsibility to consider the NGTL applications in a timely manner.

The EUB accepted that the proposed facilities were an integral component of NGTL's long-term plans to provide economic and efficient transportation service to its customers and noted that both CAPP and shippers on the NGTL system had an earlier opportunity to review these plans and had submitted some information requests to NGTL concerning the applied-for facilities. Neither CAPP nor any shippers had attended the hearing to raise any specific concerns about these facilities arising from their reviews. The EUB was also satisfied that the contract between NGTL and NCL adequately demonstrated an immediate need to commence development of the proposed facilities and that there were reasonable reserves or potential gas reserves to justify construction of the proposed facilities. The EUB rejected Westcoast's argument that it should not take into consideration the potential future use of the proposed facilities and stated that it must take into account the current and future use of facilities in order to ensure that both the short-term and the long-term public interests are being served.

\section{(v) Imperial Oil Resources Limited Application to Amend its Cold Lake Production Project Approval ${ }^{84}$}

Imperial Oil Resources Limited ("Imperial") applied for an amendment to its original approval for its Cold Lake project to allow the use of a combination of directional and horizontal wells to access the oilsand reserves beneath Leming Lake. Imperial had experienced casing failures in twenty of its wells at the Cold Lake project in 1994 and 1995 which resulted in the release of solids and fluids to the surface. Imperial already had approval to develop the resources under Leming Lake, the only issue was whether that approval should be amended to allow Imperial to develop the south Leming Lake area in the manner proposed in the subject application. Imperial stated that advances in horizontal drilling technology had enabled it to bring the proposal forward at the present time and that the immediate development of the resources under the lake was required in order to optimize resource conservation. Development of the area beneath the lake at this time would, in Imperial's view, improve the ultimate recovery of both the existing surrounding operation and the proposed new development. The EUB agreed that, with the existing drilling pads around Leming Lake being in an advanced stage of depletion, concurrent depletion was important.

Imperial submitted that new development drilling in the Cold Lake project needed to be carefully coordinated with the existing steaming operations and that it required EUB approval at this time in order to meet the current window of opportunity for 
drilling. The next opportunity would be at least two years later and this delay in drilling could result in a reserves loss of up to $100,000 \mathrm{~m}^{3}(630,000 \mathrm{bbls})$ of oil. The EUB accepted that a loss in reserves may result from a delay in drilling until the next available window.

Imperial proposed the use of a combination of conventional directional wells and long reach horizontal wells operated using cyclical steam stimulation. The EUB was satisfied that this approach represented the preferred development option since other options were not desirable due to environmental impacts.

The EUB also considered the issue of appropriate setback distances from the lake for the wells in question. The water level in Leming Lake had been dropping over several years and the distance to the 1994 water line from the closest well was 175 metres whereas the closest distance to the historic high water mark was sixty metres. Imperial maintained that the proposed well locations reflected a balance between maximizing resource recovery and environmental protection by maintaining a reasonable setback distance from the historical high water mark. If the well setback from the shoreline was increased it would reduce Imperial's ability to use conventional directional drilling techniques and would likely reduce resource recovery due to the uncertainty of the performance of horizontal well operations in this application. Imperial estimated that the higher risk from using only horizontal wells would reduce resource recovery by up to 45 percent. The EUB was satisfied that the setbacks proposed by Imperial were acceptable given the mitigative measures being implemented even though the current regulations for conventional wells generally require a setback of 100 metres from the high water mark of water bodies. The EUB acknowledged that the setbacks from water bodies were intended to minimize impacts from potential surface spills and did not provide for the type of spills or releases resulting from underground blowouts similar to those that had been experienced by Imperial at the Cold Lake project. The EUB considered that a surface release under the lake could occur under the current proposal and that such circumstance was unacceptable from an environmental point of view. The EUB indicated that if development was to proceed with wells located within the 100metre setback of Leming Lake, some supplementary protection measures must be in place to minimize or prevent impacts from potential casing failures which could result in the release of fluids to the surface.

The EUB stated that it considered potential failures near water bodies to be particularly significant given the added environmental impact, and that in its view, in the event a casing failure occurred that could not be controlled and erupted to surface in the lake, the entire area and its surroundings would be contaminated. The EUB did not accept that the detection methods proposed by Imperial would allow it sufficient time to control the size and location of any surface release, and asserted that it was highly unlikely that Imperial could isolate the contamination. In the EUB's view, all reasonable efforts should be made to avoid such an occurrence and the installation of surface or intermediate casing to cover the shales of the Colorado Group would provide assurance that the lake and near shore area would not be impacted by the operation of the near shore facilities. 
The EUB approved the application on the conditions that all wells must have surface or intermediate casing installed to cover the shales of the Colorado group and that the final casing design was subject to approval of the EUB.

(vi) Complaint by Small Explorers and Producers Association of Canada ${ }^{85}$

The Small Explorers and Producers Association of Canada ("SEPAC") filed a letter dated June 21, 1994 with the Alberta Public Utilities Board ("PUB") complaining that the rates charged by NGTL effective November 1, 1993 were unjust and unreasonable. Specifically, SEPAC objected to NGTL contracting for $540 \mathrm{MMcf} / \mathrm{d}$ of capacity on the Foothills Zone 7 facilities in Alberta. The PUB heard the complaint by way of a written hearing. As a result of the Alberta Energy and Utilities Board Act ${ }^{86}$ being proclaimed in force on February 15, 1995 the decision was issued as a decision of the EUB on July $28,1995$.

NGTL's western Alberta mainline pipeline is integrated with Zone 7 of the Foothills system which consists of various pipeline loops. Originally, Pan-Alberta Gas Limited ("Pan-Alberta") was the sole shipper on Zone 7. In 1993, NGTL's western mainline facilities were expanded in order to accommodate new shippers who wished to have their gas transported on the Pacific Gas Transmission Company expansion. As a result of a hydraulic analysis of the total capacity of the integrated system, NGTL concluded that the Foothills Zone 7 facilities were contributing $780 \mathrm{MMcf} / \mathrm{d}$ of capacity to the integrated system. As Pan-Alberta's contract was for $240 \mathrm{MMcf} / \mathrm{d}$, NGTL entered into a transportation contract with Foothills for $540 \mathrm{MMcf} / \mathrm{d}$ of Foothills Zone 7 service. This meant that NGTL customers would pay 70 percent of the Foothills Zone 7 costs.

In order to transport its gas to the Alberta-British Columbia border Pan-Alberta was paying both the NGTL toll and the Foothills toll. Other shippers paid only a single toll to NGTL. In December 1993, Pan-Alberta had entered into an agreement to restructure its gas sales arrangements with Pacific Interstate Transmission Company. A condition of this restructuring was that the Foothills Zone 7 charges would be rolled into NGTL's rates.

The EUB determined that NGTL's actions in entering into the $540 \mathrm{MMcf} / \mathrm{d}$ transportation contract with Foothills were not prudent and denied NGTL the recovery of the costs associated with this contract for the period November 1, 1993 through December 31,1994 . These costs totalled approximately $\$ 9$ million. The three reasons which were outlined for the disallowance were:

In the Matter of a Complaint in Writing by the Small Explorers and Producers Association of Canada (SEPAC) That, as a Result of a Contract Between NOVA Gas Transmission Lid. (NGT) and Foothills Pipe Lines Lid. For Transportation Service in Zone 7. The Rates, Tolls or Charges Fixed By NGT Effective November 1, 1993 Are Unjust and Unreasonable (28 July 1995), No. E95079 (EUB).

Supra note 8. 
(1) Foothills did not have any ownership or entitlement to pipeline capacity created by the pipeline pressure resulting from compression on then NGTL system;

(2) Foothills should have been paying NGTL for compression service pursuant to the terms of the operating agreement between NGTL and Foothills; and

(3) the whole area was so uncertain that NGTL should have been able to negotiate a better deal with Foothills rather than just assuming Foothills was entitled to the capacity.

NGTL filed an application with the EUB for a review and variance of this decision on September 22, 1995 and has filed a notice of motion for leave to appeal to the Alberta Court of Appeal. The implementation of this decision has been suspended by the EUB pending disposition of NGTL's application for review and variance. No decision on the review and variance application has been issued as of May 31, 1996.

\section{(vii) NGTL 1995 General Rate Application Phase ${ }^{87}$}

This decision on NGTL's 1995 tariff and general rate application represents the first full consideration of NGTL's rates, tolls and tariffs under the Gas Utilities Act. ${ }^{88}$ Prior to 1995 NGTL's rates for service had been regulated on a complaint basis. The EUB adopted the former practice of the PUB with respect to other utilities' rate applications in that the hearing of NGTL's application was split into two phases. Phase I dealt with matters of revenue requirement and Phase II dealt with rate design, cost allocation among rate groups and conditions of service. Phase I was heard in August 1995 and the decision was released on January 8, 1996. The decision on Phase II was released on June $13,1996 .^{89}$

The EUB reduced NGTL's total applied-for revenue requirement of $\$ 1.181$ billion by about 10 percent to $\$ 1.062$ billion. Tolls for 1995 were increased by 4.3 percent above the 1994 levels compared to the 16 percent increase requested by NGTL.

The EUB reduced NGTL's depreciation expense by $\$ 30$ million or approximately 15 percent of the applied-for amount. NGTL had presented depreciation rates which had last been reviewed in 1980. The EUB determined the evidence put forth by NGTL in support of its recommendation to be not only incomplete but also so dated as to be of limited usefulness. As requested by several intervenors, the EUB directed NGTL to carry out a detailed depreciation study of its operations and file it as part of its next general rate application.

89 Application for 1995 Tariff and General Rates, Nova Gas Transmission Lıd. (13 June 1996), Decision U96055 (EUB). 
The EUB heard extensive evidence on the issue of capital structure and fair return and determined that a deemed common equity component of 32 percent was appropriate with a rate of return of 11.25 percent. The EUB pointed out that its assessment of business risk in this proceeding should provide a basis for evaluating future changes to NGTL's capital structure and that the EUB did not expect to review these risks in detail on an annual basis unless there were material changes.

The EUB adopted a global approach to its review of NGTL's operating and maintenance expenses rather than focusing on selected items. This is similar to the approach taken by the NEB with respect to Westcoast's tolls. ${ }^{90}$ The EUB believed that NGTL could have taken further steps to control and reduce its operating and maintenance expenses and reduced the applied-for $\$ 280$ million expense by $\$ 10$ million.

The issue of NGTL's transportation at others' expense generated a great deal of attention at this hearing. Canadian Western Natural Gas Company Limited and Northwestern Utilities Limited (collectively the "Utilities") had advanced a proposal whereby the costs incurred on their system by producers which were transporting gas to the NGTL system would be rolled into NGTL's rates. Currently producers located in the Utilities' service areas often have to pay both a toll on the Utilities' systems and the NGTL toll. The Utilities' proposal only applied to producers wanting to get onto the NGTL system. It did not apply to consumers who take gas from the NGTL system and then transport it on the Utilities' system to their plant gate. The EUB did not adopt the Utilities' proposal. It noted that, unlike the Foothills system, the Utilities' systems were separate and independent systems operating largely in different areas of the province than NGTL. The fact that shippers were utilizing both NGTL's system and the Utilities' systems was a reflection of the various conditions under which pipeline systems had developed in Alberta and did not constitute undue discrimination.

With respect to the Foothills system, NGTL had taken an assignment of Pan-Alberta's $240 \mathrm{MMcf} / \mathrm{d}$ transportation contract on Zone 7. NGTL now had the entire capacity on Zone 7 under contract, as it had previously entered into a 540 MMcf/d contract for the remaining capacity. In the SEPAC decision, ${ }^{91}$ the EUB found that NGTL could not include the costs associated with this contract into its rates for the November 1, 1993 to December 31, 1994 period. ${ }^{92}$ The EUB approved both the roll-in of the $240 \mathrm{MMcf} / \mathrm{d}$ and the roll-in of the $540 \mathrm{MMcf} / \mathrm{d}$ for NGTL's 1995 tolls. The EUB referred to the unique history of the Foothills facilities, the previous roll-in of Foothills Zone 6 facilities into NGTL's rates, and the unreasonableness of Pan-Alberta paying two tolls for transportation on identical routes as NGTL's shippers as reasons supporting its decision to approve the $240 \mathrm{MMcf} / \mathrm{d}$ roll-in.

With respect to the $540 \mathrm{MMcf} / \mathrm{d}$ roll-in, this rate decision does not contain a discussion as to why the reasoning in the SEPAC decision had not been followed. Several intervenors had, however, pointed out certain differences from the situation 
when the SEPAC decision was rendered. SEPAC and CAPP have filed an application with the EUB for a review and variance of this aspect of this rate decision and have filed a notice of motion for leave to appeal to the Alberta Court of Appeal. No decision on the review and variance application has been issued as of May 31, 1996.

The EUB also approved NGTL's extensive use of deferral accounts which would shield it from various external factors beyond its reasonable control with carrying charges thereon to be calculated at NGTL's composite rate of return. As NGTL had over-collected on interim rates that had been in effect since January 1, 1995, the EUB ordered NGTL to make refunds to its customers retroactive to January 1, 1995 with appropriate carrying charges.

(viii) Canadian Western Natural Gas Company Limited and Northwestern Utilities Limited Core Market Direct Purchase Service Application ${ }^{93}$

In March 1995 the Government of Alberta enacted regulations which enabled all Alberta gas consumers to buy natural gas directly from suppliers. Pursuant to these regulations Canadian Western Natural Gas Company Limited ("CWNG") and Northwestern Utilities Limited ("NUL") filed a joint application to the EUB to set rates, terms and conditions for the provision of direct purchase services to core market customers. Core market customers are defined as Alberta residential, commercial and institutional gas consumers who do not have alternative sustainable fuel sources. On May 31, 1996 the EUB released its decision on the utilities' filings on rates for both buy/sell and transportation service offerings for core customers. The EUB also addressed the utilities' proposed Service Regulations for buy/sell and transportation service, the Buy/Sell Gas Purchase Contract, the Core Market Transportation Service Agreement and certain other documents.

In this decision the EUB indicated that it was attempting to balance the interests of those parties who wanted core market access without restrictions with those of other parties whose primary concern was to protect the remaining sales customers of the utility. The EUB recognized that this decision was the initial step in what was likely to be an evolutionary process in the development of core market direct purchases in Alberta. The EUB indicated that it was not attempting to either promote or discourage the use of core market direct purchase service but was trying to provide a framework which would not provide an economic bias either for or against core market direct purchases.

The key elements of the EUB's decision are as follows: 
(1) The transportation service rate for small, temperature-sensitive, customers was set at the equivalent sales rates less the gas cost recovery charge. Daily load balancing is not required under this service but adjustments will be made monthly to correct any imbalances.

(2) The buy/sell service was established on a "buy" price by the utilities equal to the average price of monthly intra-Alberta spot gas on the NOVA system as published by Canadian Enerdata Ltd. (an "AECO-C/N.I.T. price") and a "sell" price to the core customer equal to the utilities' gas cost recovery charge. In order to achieve any substantial savings the core market customer must purchase gas at a price lower than the AECO-C/N.I.T. price as a significant portion of the Utilities' portfolio on which the gas cost recovery charge is based consists of purchases with prices indexed to the AECO-C/N.I.T. price.

(3) The buy/sell service allows umbrella agreements under which an agent can aggregate the requirements of individual core customers.

(4) The buy/sell service requires a maximum daily delivery quantity based on a 53 percent load factor, a winter (five months) quantity equal to 55 percent of the annual quantity, a summer (seven months) quantity equal to 45 percent of the annual quantity, and a delivery point at Carbon, Alberta.

(5) The first opportunity to commence core market direct purchases will be November 1, 1996 and customers can commence service on the first day of any month thereafter.

(6) If a customer gives five months notice of its intention to commence either buy/sell or transportation service it can do so with no transition cost charge.

(7) The minimum notice period will be two months but such shorter notice period requires a transition cost charge of $\$ 0.05 / \mathrm{GJ}$ for $\mathrm{CWNG}$ and $\$ 0.03 / \mathrm{GJ}$ for NUL which will apply over the first twelve months of the direct purchase arrangement.

(8) A two month notice period with no transition cost charge was approved for customers who desire to renew or terminate buy/sell or transportation service.

(9) A failure to provide notice of renewal of direct purchase service will be treated as a return to sales service.

(10) The utilities' proposed administration fees of $\$ 5.00$ per customer account per year and $\$ 125.00$ per month for each umbrella core transportation service agreement and each umbrella core buy/sell gas purchase contract were approved.

(11) The EUB declined to approve the customer information documents filed by the Utilities as EUB approval might be construed by customers as a 
recommendation by the EUB to use the Utilities as a supplier of natural gas rather than a direct marketer.

(12) The EUB rejected the utilities' proposal that all customers under an agent's umbrella agreement be jointly and severally liable as this would severely inhibit customers from using direct purchase services.

(ix) Encal Energy Limited Application to Relicense

Pipeline to Transport Sour Gas in the Rimbey Area ${ }^{94}$

Encal Energy Limited ("Encal") applied for approval to relicense one of its pipelines from sweet to sour gas service. The EUB was satisfied that a sour gas pipeline was required in the area and believed that the use of an existing pipeline system, provided it is technically suitable and safe, is preferable to the construction of a new pipeline since it minimizes costs as well as social and environmental impacts. The EUB was not, however, prepared to approve the application based on the information provided by Encal and required Encal to file additional information, failing which the application would be denied.

One of the reasons that the EUB refused to grant Encal's application was that it was not convinced that Encal had fully examined all reasonable alternatives, and Encal did not provide sufficient evidence to indicate why alternative routes were rejected. Another reason relied upon by the EUB in refusing to approve the application without further information was the fact that Encal had not provided sufficient evidence to convince the EUB that it had thoroughly evaluated the operation and maintenance of the pipeline and had measures in place to ensure the safe operation of the line.

The EUB also reiterated the need for people in the vicinity of a proposed energy development project who may be directly or adversely affected by such a project to be given the opportunity to learn about the proposed development and its potential impacts. In the case of a pipeline project, this includes providing residents with information about the nature of the hazard and actions, such as indoor sheltering, that can provide additional protection during the unlikely event that a pipeline failure does occur. In this case, Encal was requested to provide confirmation that all residents within the emergency response planning zone had been notified about the project and its potential impacts. 


\section{b. Recommendations of EUB Examiners}

\section{(i) Baytex Energy Ltd. Application for a Well Licence} and Permit to Construct a Single Oil Well Battery"s

In this matter a landowner filed an objection with the EUB opposing the issuance of a well licence to Baytex Energy Ltd. ("Baytex"). The landowner wanted Baytex to move the proposed well off his property since he used that land for hunting and was concerned about the impacts that the well and associated flare would have on wildlife. The landowner was also concerned that the wellsite would provide random access to his property, and he believed that Baytex had negotiated in bad faith.

The examiners determined that there was no evidence to support the landowner's concern that the flaring of the gas production for a short duration of time would cause fewer animals to remain in the area and therefore reduce his hunting prospects. Given the landowner's concern about unauthorized access to the wellsite and thus to his property, the examiners believed that it would be appropriate to fence the entire lease area and to install a locked gate at the established access point to the site. What is noteworthy in this case is that the examiners did not believe that Baytex conducted meaningful negotiations with the landowner because it relied solely on the services of contract land personnel to acquire the surface lease and address the concerns that the landowner raised. The examiners indicated that, although they understood that this was common industry practice, when a conflict arises the company is encouraged to have someone with the authority to make decisions directly involved in the efforts to resolve the conflict. The examiners pointed out that it is not surprising that the landowner would find the negotiation process to be unacceptable when the person with whom he or she is negotiating has little direct authority to make decisions on behalf of the company. The examiners pointed out that the applicant is at risk if it does not conduct meaningful negotiations as expected by the EUB. The hearing can be delayed to allow further negotiations to take place or the application can be denied without prejudice if it is clear to the examiners that all options have not been fully explored by the company. The examiners also pointed out that there must be open and free communication between the parties and that the landowner should not be made to feel that he or she is being backed into a corner with no way out and with no opportunity to discuss his or her concerns in a meaningful manner. In this case it was apparent that further negotiations would likely be unsuccessful, and there were no alternative sites which merited further consideration. Accordingly, Baytex's application was approved.

(ii) Cabre Exploration Ltd. Application for Injection/Rateable

Take/Common Carrier/Common Processor Declarations ${ }^{96}$

Cabre Exploration Ltd. ("Cabre") applied for: 
(1) an order declaring Unocal Canada Resources ("Unocal") to be a common carrier of production from the Kakwa Cardium A Pool (the "A Pool");

(2) an order declaring Unocal to be a common processor of gas produced from the A Pool through the Unocal plant located in the area;

(3) an order distributing production among wells in a part of the A Pool; and

(4) an amendment to an approval respecting a scheme for gas cycling of the gas cap and for enhanced recovery of oil by gas injection in a part of the A Pool.

The A Pool is an oil pool with an associated gas cap, the northern portion of which is included in the Kakwa Cardium A Unit (the "Unit") which was operated by Unocal. Since 1984 the northern part of the A Pool had been subject to a scheme for gas cycling to obtain maximum recovery of liquids from the gas cap and for enhanced recovery of oil by gas injection. Four wells were used for injection of gas into the A Pool. Cabre was not a participant in the Unit and had drilled a well which encountered the A Pool. This well did not have EUB approval to produce from the gas cap associated with the oil pool and therefore remained shut in. This well was also not tied into any gathering system. Cabre wished to produce oil from this well on the same terms and conditions as oil was being produced from the Unit. In order to participate in the Unit's existing enhanced recovery scheme Cabre submitted that it had no reasonable alternative to using the Unit facilities for gas reinjection. The issues in this case were:

(1) the need for an order requiring the Unit to inject gas on Cabre's behalf;

(2) the need for a common carrier and a common processor order; and

(3) the need for a rateable take order.

Cabre submitted that it was unable to produce its well since it was not a participant in the existing enhanced recovery scheme and did not have an injection well of its own in the A Pool. Cabre was prepared to produce without an order requiring gas replacement or cycling if so directed by the EUB but it did not consider such a scenario to be the optimum way of producing the pool. Cabre indicated that it could not locate any currently unleased lands around the A Pool for the purposes of drilling its own injection well and that drilling such a well on the fringe of the pool would have an even greater geological risk and worse economics than drilling an injection well on its existing lease.

Cabre had been unable to negotiate a satisfactory commercial arrangement for use of the Unit's injection facilities since the Unit had only offered to inject gas on Cabre's behalf for voidage replacement for production from its well of up to $1310^{3} \mathrm{~m}^{3} / \mathrm{d}(459$ $\mathrm{mcf} / \mathrm{d})$ of gas, whereas Cabre proposed to produce a minimum of $811^{3} \mathrm{~m}^{3} / \mathrm{d}(2.86$ MMcf/d) of gas in order to obtain its share of pool reserves. The Unit submitted that Cabre's well should not be placed on production unless gas was injected into the A Pool to maintain voidage replacement at 100 percent. The Unit did not propose production without voidage replacement because of pool conservation issues. If, 
however, Cabre was allowed to produce its well without voidage replacement, the Unit maintained that it should also be allowed to produce in the same manner. The Unit argued that Cabre had other alternatives to using the Unit injection facilities and maintained that it was economic for Cabre to drill its own injection well.

Two of the three examiners found that although the most preferable option would be for Cabre's well to produce with full voidage replacement it would be preferable for Cabre's well to produce without voidage replacement rather than remain shut-in in order to minimize the loss of wet gas and retro-grade liquids. The majority was not prepared to recommend that the Unit be allowed to produce without voidage replacement. Since production of Cabre's well without voidage replacement was not the ideal solution, the examiners went on to examine whether Cabre had any reasonable alternatives. They found that the Unit offer to inject gas to replace production of up to $1310^{3} \mathrm{~m}^{3} / \mathrm{d}(459 \mathrm{mcf} / \mathrm{d})$ of gas from Cabre's well would not allow Cabre to obtain its share of reserves and therefore was not a reasonable alternative for Cabre from an equity point of view. They agreed with Cabre's submission that using the Unit's injection facilities represented the most practical, orderly and efficient alternative for developing Cabre's reserves. They found that in the circumstances, without some action by the EUB, Cabre was unlikely to be afforded a reasonable opportunity to obtain its share of liquids. The majority believed that there were two possible recommendations: first, to allow Cabre to produce its well without voidage replacement while the Unit continues to replace voidage for Unit production; or second, to seek an order requiring the Unit to inject on Cabre's behalf. Since the second alternative would be a very significant action by the EUB and would constitute a major step towards forced unitization, the majority felt that an order to inject on Cabre's behalf should be undertaken only where there is no other workable alternative to allow the applicant to obtain its fair share of reserves. In this case, the majority believed that there was an alternative and therefore did not believe that it would be appropriate to recommend the issuance of an order requiring the Unit to inject gas on Cabre's behalf. Accordingly, the majority was prepared to allow Cabre to produce the well without any voidage replacement.

The majority indicated that a successful applicant for a common carrier order is required to satisfactorily demonstrate that:

(1) producible reserves are available for transportation through an existing pipeline;

(2) there is a reasonable expectation of a market for the substance proposed to be transported by the common carrier operation;

(3) the applicant can not make reasonable arrangements to use the existing pipeline; and

(4) the proposed common carrier operation is either the only economically feasible way or clearly the most practical way to transport the substance in question, or is clearly environmentally superior. 
With respect to a common processor order, the majority indicated that a successful applicant must satisfactorily demonstrate that:

(1) producible gas reserves exist and gas processing facilities are needed;

(2) reasonable arrangements for the use of processing capacity in the existing plant can not be agreed on by the parties; and

(3) a common processor order is either the only economically feasible way or clearly the most practical way to process the gas in question, or is clearly environmentally superior.

The majority concluded that Cabre's reserves were being drained and, in view of the recommendation that Cabre be allowed to produce without voidage replacement, the majority considered Cabre's alternatives for developing its reserves to be building all its own facilities, using the Unit facilities, or transporting its gas to the Cutbank plant for processing. The majority believed that the option of Cabre building its own processing plant and pipelines to get its gas to market would be an unnecessary duplication of facilities and, although the Cutbank alternative was an economic option, it would involve building more new facilities including a longer pipeline than using the Unit facilities. Accordingly, these two options would also increase surface disturbance and cause some impact on the environment. The majority therefore concluded that utilization of the Unit facilities represented the most desirable option in this case. The majority noted that negotiations to allow Cabre access to the Unit facilities on mutually acceptable terms had failed, and that since the Unit had never offered to allow Cabre the use of Unit facilities in situations where Cabre would be allowed to produce without voidage replacement, Cabre would not have unequivocal access to Unit facilities in the absence of common carrier and common processor orders. The majority was therefore prepared to recommend that the orders be granted.

Cabre submitted that since it had been unsuccessful in its attempts to negotiate what it considered to be an equitable rate of production from its well, its reserves continued to be drained and a rateable take order was needed to ensure that it obtained an equitable share of pool production. Cabre presented evidence indicating that 7.4 percent of production from the application area should be allocated to Cabre and 92.6 percent to the Unit. The Unit submitted that there was no need for a rateable take order since there was no inequitable drainage of Cabre's reserves. However, if a rateable take order was to be issued, the Unit calculated that 1 percent of the reserves should be allocated to Cabre and 99 percent to the Unit. The majority stated that in previous decisions on rateable take matters, the EUB had indicated that an applicant requesting an order distributing production among wells in a pool would be required to demonstrate that it is being deprived of the opportunity to obtain its share of production from the pool. The EUB would then determine whether or not the applicant has and would continue to have a reasonable opportunity to produce reserves more or less in proportion to the reserves associated with its well. The applicant must show that drainage is actually occurring or would occur as a result of the applicant not having an opportunity to produce its share of gas. In this case the majority felt that the reserves underlying the 
section on which Cabre's well was located were being drained and would continue to be drained because of the failure of the parties to come to a mutually satisfactory arrangement allowing production from Cabre's well. The majority was satisfied that Cabre had made reasonable attempts to resolve the issue of what rates its well should produce at and that it was being deprived of a reasonable opportunity to produce its well. Therefore, the majority was prepared to recommend that an order be issued to provide for equitable withdrawals from the pool. In this case the majority felt it would be equitable to allocate 6.8 percent of total production to Cabre's well and 93.2 percent to the Unit's wells.

The examiner in the minority felt that there should be a "level playing field" for both operators and that it would not be fair for the Unit to be required to replace its voidage while Cabre was not required to do so. Accordingly, until such time as Cabre was in a position to have voidage replacement, he was not prepared to issue common carrier, common processor, or rateable take orders and he recommended that Cabre's application be denied.

In light of the recommendations of the examiners, the EUB decided to initiate a review of the approval of the Unit's gas cycling scheme at a hearing and stated that the final disposition by the EUB of Cabre's application would be considered in the context of such review. The EUB also requested that it be advised of any developments or agreements made with respect to this matter prior to the hearing.

\section{(iii) Jordan Petroleum Limited Application for a Well Licence ${ }^{97}$}

Jordan Petroleum Limited ("Jordan") originally obtained a licence to drill a well in November 1995. In December 1995, the EUB received a submission from the surface landowners and residents on the quarter section where the well was proposed to be drilled. The landowners' submission requested that Jordan's licence be rescinded and a public hearing was convened to review the application in March 1996. Among the concerns raised by the landowners were the proximity of the proposed well site to the landowners' residences and the route of the applied-for access road. The landowners also felt that they were being asked to consent to operations in a piecemeal fashion and were thereby deprived of the opportunity of appraising the entire scope of the project.

Based on the sketchy information provided by Jordan, the examiners were not convinced that the well location requested by Jordan was critical. The examiners believed that Jordan's proposal with regard to its access road could have been more accommodating to the landowners' farming operations but that there was little evidence to indicate that Jordan was willing to make any concessions in this regard. The examiners were concerned about the apparent lack of accommodation and negotiation by Jordan and believed that the public consultation process envisioned by the EUB had not taken place in this case. It appeared from the evidence that Jordan did little more than attempt telephone contact with affected residents or make a casual contact to ask predetermined questions. The examiners felt that details of the type of well being 
drilled and the potential impact it would have, should have been provided in early discussions with affected residents so that they could understand the proposal, ask questions, and make informed decisions. As a result, the examiners recommended that Jordan's well licence be cancelled even though the examiners had no reason to believe that the proposed well could not under the right circumstances be safely drilled and operated so as to protect public safety and health and minimize the environmental impact.

\section{c. Informational Letters}

\section{(i) Progress Report Requirements for Miscible Flood Schemes ${ }^{98}$}

IL 96-2 contains revised reporting requirements for enhanced oil recovery schemes that use a miscible flood displacement process. The reporting process consists of two parts. Part one is an annual data submission which includes only data elements that cannot be internally generated by the EUB. Part two is an annual meeting at which the scheme operators are expected to make a presentation on recent scheme performance, compliance with approvals, technical matters and future plans. Annual meetings will be coordinated by EUB staff and will include representatives of the scheme operator, the EUB and the Department of Energy staff.

\section{(ii) Suspension and Reclamation of Upstream Oil and Gas Facilities ${ }^{99}$}

IL 96-3 announced the Memorandum of Understanding ("MOU") reached between the EUB and Alberta Environmental Protection ("AEP"). The MOU is intended to delimit the regulatory rules of AEP and the EUB, avoid regulatory duplication, and enhance protection of the public interest. Pursuant to the MOU, the EUB is responsible for ensuring proper operation, suspension and abandonment activities at all upstream oil and gas facilities. AEP is responsible for all decontamination and land reclamation activities. The EUB is responsible for ensuring the safe and proper operation and maintenance of all active upstream oil and gas facilities, including proper oilfield waste management. AEP is responsible for ensuring that both on- and off-lease contamination at all active upstream oil and gas facilities is addressed by the operator. For all facilities where the EUB suspects that contamination has occurred, the EUB will require operators to contact AEP directly to determine if further delineation, containment or clean-up work is needed. Accordingly, in the future operators can expect to have more interaction with AEP during the clean-up process. At the same time, the EUB intends to focus greater efforts on the prevention of contamination and the timely suspension and abandonment of non-economic facilities. 
(iii) Requirements for Applications for Permits to Remove Natural Gas from Alberta ${ }^{100}$

Effective May 7, 1996 the EUB in IL 96-5 revised the information required in support of an application for a permit to remove natural gas from Alberta. The revised requirements for short-term and long-term gas removal permits are contained in application forms attached to IL 96-5.

Information no longer required for short-term gas removal applications includes the following:

(1) the market areas where gas is to be sold;

(2) the types of markets to be served under a permit;

(3) the location of the points of removal of gas from the province;

(4) evidence that the volume of gas, subject to the permit, is available for removal from Alberta on an overall provincial basis;

(5) a discussion of pricing matters;

(6) a discussion of transportation matters; and

(7) a discussion of corporate affiliations among the applicant, the intended customer and producers.

Existing approvals will not be limited to the removal points specified in the permit or to any specific market type or market area.

Information no longer required for long-term gas removal applications includes the following:

(1) the maximum daily and annual rates of gas removal during the term of the proposed permit;

(2) the location of the points of removal of gas from the province;

(3) evidence that the volume of gas, subject to the permit, is available for removal from Alberta on an overall provincial basis; and

(4) a discussion of corporate affiliations among the applicant, the intended customer and producers. 
The EUB also strongly encouraged any company holding a number of long-term gas removal permits to consolidate them into a single permit and to establish a corporate reserves pool which could be used to supply any market subject to the permit. IL 96-5 also advises companies that the EUB is to be informed immediately of those situations where the volume and term associated with an existing long-term gas removal permit remain unchanged but there is a change in the type of market being served under the permit or a significant change in the structure of the pricing arrangements from that described in the application which resulted in the existing permit. The EUB will review the changes and initiate a review of the permit if the EUB is concerned that the changes may be adverse to the public interest.

\section{(iv) Solution Gas Conservation and Emissions Reduction ${ }^{101}$}

IL 96-6 advises operators that the EUB is pursuing a two-phase program to assist both operators and the public in addressing issues that are related to the flaring of solution gas. The EUB has initiated a multi-stakeholder review of its solution gas and emissions policy objectives and associated implementation methods. In the interim the EUB will continue to apply the current economic and local environmental criteria used to determine the desirable extent of emission reduction or solution gas conservation. When it is determined by the EUB that a reduction in flaring is required, the EUB's expectations and time lines will be set out clearly and will be open for discussion with affected companies at the time they are set out. Once a decision on reasonable targets has been reached, the EUB will expect companies to meet their obligations. Where the conservation of solution gas appears to be economic, the following policy will apply:

(1) upon written notice of gas conservation being required, an operator will have a specified period of time to implement a gas conservation scheme; and

(2) if, at the end of this period the scheme has not been implemented, the flaring facility and production will be immediately shut in until an acceptable solution gas conservation scheme is implemented.

Where EUB staff believe that emissions must be reduced in order to meet local environmental objectives, the following policy will be used:

(1) upon written notice that emissions of gas must be controlled, an operator will have a specified period of time to implement appropriate measures; and

isv'(2) if, at the end of this period the scheme or disposal process has not been implemented, one of the following actions will occur:

(a) a monthly flare limit will be imposed;

(b) production will be limited to specified rates; or

(c) a strict gas to oil ratio limit will be imposed and applied. 
(v) EUB/AEP Memorandum of Understanding on the Regulation of Oilsands Developments ${ }^{102}$

IL 96-7 announces the Memorandum of Understanding between the EUB and AEP regarding their respective roles and responsibilities in the approval and regulation of oilsands development in the province. A significant feature of the MOU is a new coordinated regulatory approval process that will be followed for major oilsands development applications which require approvals under both the Oil Sands Conservation $\mathrm{Act}^{103}$ and the Environmental Protection and Enhancement Act. ${ }^{104}$ Although separate approvals will continue to be issued by the EUB and AEP, the application processing activities will be integrated, and applications to the EUB and AEP for a major oilsands development will be filed concurrently with each agency.

\section{d. Interim Directives}

\section{(i) EUB Guide G-55 Materials Storage Requirements ${ }^{105}$}

ID 95-3 highlights the materials storage requirements for the upstream petroleum industry and introduces EUB Guide G-55 which contains storage requirements for those materials produced, generated or used by the upstream petroleum industry including associated wastes. The EUB will expect any storage device installed after January 1, 1996 to meet the requirements specified in Guide G-55. Operators of facilities constructed and operated prior to January 1, 1996 will be required to demonstrate that their storage practices, facilities and containment devices meet the intent of the requirements within Guide G-55. It is expected that all above ground and underground tanks will be inspected or tested prior to October 31, 2001. Above ground tanks with a volume greater than five cubic metres must have a secondary containment system, a leak detection system and an exterior coating to protect them from the weather. Underground tanks must have a leak detection system and in most circumstances a secondary containment system. Operators must maintain accurate inventory inspection and leak detection records for two years and, where applicable, groundwater monitoring records for five years.

\section{(ii) EUB Guide 56 Energy Development Applications ${ }^{106}$}

ID 96-2 introduces EUB Guide 56 which summarizes and presents the EUB's expectations and requirements for certain energy development applications. It provides a new integrated application process for specific oil and gas facilities and pipelines including oil and gas batteries, gas processing facilities, compressor stations, surface installations associated with pipelines and all pipelines except sewage, low pressure gas

(18 April 1996), No. IL 96-7 (AEUB) [hereinafter IL 96-7].

R.S.A. 1980, c. O-5.

Supra note 12.

Storage Requirements for the Upstream Petroleum Industry (26 July 1995), No. ID 95-3 (EUB) [hereinafter ID 95-3].

Facility Application Requirements (9 April 1996), No. ID 96-2 (EUB) [hereinafter ID 96-2]. 
distribution pipelines and municipal water pipelines. It should be noted that Guide 56 does not cover wells. Essentially, Guide 56 enables an applicant to submit one application package ("Energy Development Application") to include all facilities and pipelines associated with a specific project instead of filing a separate application for each component of the project. Guide 56 sets out a new approach to facility and pipeline regulation. For example, there is a greater onus upon the applicant to ensure that the Energy Development Application which it files is complete and accurate. Rather than issuing a deficiency letter, the EUB will now simply close the file when an application is severely deficient. The applicant will then have to reapply with a new, complete and accurate application package and will have to pay a new application fee. Applications that meet all requirements will be processed as routine applications and more quickly than non-routine applications. Applicants will no longer routinely submit supporting documentation with their application and instead are required to keep this information on file and readily available for audit by the EUB. One exception to this rule is where an application will be considered at an EUB hearing, in which case all information supporting the application must be submitted to the EUB. All first-time applicants must file a corporate profile with the EUB and have it accepted by the corporate compliance section. The EUB now conducts a corporate check before an application is processed and companies with a poor compliance record will have their applications delayed until outstanding liabilities and obligations to the EUB have been addressed.

Instead of reviewing applications for completeness, informing the applicants of deficiencies and fielding numerous calls about the regulations, the EUB has implemented an audit system in order to confirm regulatory compliance and to help measure the effectiveness of the integrated application process. Applicants are required to keep all records relating to their application on file for one year following the approval date and these records must be submitted to the EUB within ten working days of written notification that an application has been selected for audit.

Prior to submitting an Energy Development Application, an applicant will have to carry out a public involvement program in order for an Energy Development Application to be processed as a routine application. The applicant will have to affirmatively state that industry and public notice requirements have been met and that there are no outstanding public or industry objections. The appendix to Guide 56 contains a set of public involvement guidelines to assist applicants in carrying out their public involvement programs. These guidelines apply to all new facilities and all modifications to existing facilities. The guidelines state that the applicants are expected to take their public involvement responsibilities and obligations very seriously and that it is necessary that all of the activities outlined in the guidelines be carried out before an application is submitted. Generally speaking, every land owner or occupant within a prescribed radius must be contacted and must not object to the project. If a party does object, the applicant is expected to attempt to address the concerns raised and to reconcile differences. Any objections or concerns that are raised and which are not resolved must be indicated by checking the appropriate box on the Energy Development Application and a summary of the outstanding issues must be attached to the 
application. In such cases the application will be considered non-routine and the EUB will review the circumstances and may hold a hearing to consider the application.

In addition to the public involvement guidelines, the appendix to Guide 56 contains proliferation guidelines for new facilities. The EUB has accepted the public's view that there is a need to avoid facility proliferation whenever possible and practical. Accordingly, before submitting an application an applicant is required to investigate the ability to use alternate facilities or pipelines. With respect to significant sour facilities, an applicant wishing to construct such facilities is required to identify and contact all oil and gas reserve owners and operators of all similar sour facilities within the prescribed radius. These parties must be provided with a written overview of the proposed facility including location, type and design capacities. The onus is then on these parties to raise any concerns or objections to the proposal. An applicant should evaluate the feasibility of upgrading any existing facility and entering into commercial arrangements with existing operators. With respect to other facilities and pipelines the EUB does not prescribe the area of investigation. Instead the applicant must determine what it considers to be a reasonable area of investigation. The EUB indicated that it is in the applicant's best interest to do so since failure to do so may result in those affected filing an objection to the EUB in which case the matter may end up going to a public hearing if the matter cannot be resolved.

The appendix to Guide 56 also contains technical guidelines to assist those submitting pipeline applications, production measurement guidelines, and lists the relevant interim directives and informational letters with which an applicant must comply.

\section{BRITISH COLUMBIA}

1. British Columbia Utilities Commission

a. Decisions

(i) Review of Buy/Sell Deliveries of Natural Gas to the Core Market ${ }^{107}$

The British Columbia Utilities Commission ("BCUC") conducted a written hearing to review issues relating to the supply of gas to core market customers and to direct purchases using the buy/sell mechanism established in its March 11, 1993 decision. In its July 7, 1995 decision, ${ }^{108}$ the BCUC amended its "Rules for Energy Supply Contracts" to remove any requirement for a gas supply portfolio average term of contract for core market consumers. Individual baseload gas supply contracts are now required to have a minimum term of one year and sixty days notice for termination. Direct purchases utilizing the buy/sell mechanism were also facilitated by including shorter notice periods and a simplified form of standard contract. No. G-58-95 (BCUC). 
(ii) British Columbia Hydro and Power Authority Application for Review ${ }^{109}$

British Columbia Hydro and Power Authority ("BC Hydro") had requested a review of certain BCUC directives set out in the BCUC's November 24, 1994 decision on BC Hydro's revenue requirements for 1994/95. ${ }^{110}$ In the 1994 decision, BC Hydro was ordered to utilize certain integrated resource planning guidelines ("IRP Guidelines") which had been implemented by the BCUC in 1993. These guidelines specified certain requirements for interface between a utility and the public in the utility's planning activities. BC Hydro requested a review of the order to comply with the IRP Guidelines on the basis that it was beyond the BCUC's jurisdiction to make such an order. BC Hydro's reconsideration application was denied by the BCUC on October 17, 1995."'1 BC Hydro had also appealed the 1994 decision to the British Columbia Court of Appeal which rendered its decision on February 23, 1996."12

The Court of Appeal found that there was evidence supporting BC Hydro's assertion that the bulk of the IRP Guidelines which were the subject of the BCUC's order could be characterized as requiring BC Hydro to include a public consultation process in BC Hydro's resource planning initiatives and to be guided by the views and information provided by the members of the public in undertaking its resource planning responsibilities. The Court found that the functions that the legislature had entrusted to the BCUC were related to the grant of a monopoly through the certification of public convenience and necessity process and the supervision of the utility's use of property dedicated to service as a result of the certification process. The Court reviewed the sections of the Utilities Commission $A c t^{13}$ relating to $\mathrm{BC}$ Hydro and found that the integrated resource planning process was specific to the planning phase of the utility's response to its statutory obligations. The implementation of the IRP Guidelines by order of the BCUC was found to be beyond the BCUC's jurisdiction as it was not related to the certification process as such, or to the supervision of the utility's use of its property devoted to the provision of service. The Court held that taken as a whole, the did not reflect any intention on the part of the legislature to confer upon the BCUC jurisdiction to determine the manner in which the directors of a utility manage its affairs. This was for the management of BC Hydro to address.

(17 October 1995), No. G-86-95 (BCUC).

(24 November 1994), No. G-89-94 (BCUC).

Supra note 109.

British Columbia Hydro and Power Authority v. British Columbia (Utilities Commission), [1996]

B.C.J. No. 379 (C.A.) (QL).

S.B.C. 1980 , c. 60 . 